Review article

https://doi.org/10.17308/kcmf.2021.23/3526

\title{
The development of methods for the research and synthesis of solid phases by the scientific school of Ya. A Ugai. Review
}

\author{
G. V. Semenova ${ }^{\bowtie}$, A. Yu. Zavrazhnov \\ Voronezh State University, \\ 1 Universitetskaya pl., Voronezh 394018, Russian Federation
}

\section{Abstract}

The scientific school founded by Yakov A. Ugai has existed at Voronezh State University for over fifty years. One of its focus areas has been the development of physics and chemistry for obtaining solid phases in systems with volatile components. This determined the necessity to develop methods for the investigation of vapour pressure (tensimetric methods). This article only focuses on some of the works by the VSU staff dedicated to the study and construction of $P-T-x$ diagrams. This review analyses phase equilibria and the nature of the intermediate phases in the $\mathrm{A}^{\mathrm{IV}}-\mathrm{B}^{\mathrm{V}}, \mathrm{A}^{\mathrm{IV}}-\mathrm{B}^{\mathrm{V}}-\mathrm{C}^{\mathrm{V}}$, and $\mathrm{A}^{\mathrm{III}}-\mathrm{B}^{\mathrm{VI}}$ systems. Owing to the special nature of the cation-cation and anion-anion bonds, these compounds have highly specific properties that make them promising materials (2D materials in particular). The article presents an overview of works devoted to the construction of $P-T-\chi$ diagrams and the investigation of defect formation processes in binary and ternary systems based on $\mathrm{A}^{\mathrm{IV}} \mathrm{B}^{\mathrm{V}}$ compounds. It should be emphasised that the known techniques needed updating due to the high values of vapour pressure. This allowed conducting experiments at pressures of about 35-40 atmospheres. The study of the $\mathrm{A}^{\mathrm{III}}-\mathrm{B}^{\mathrm{VI}}$ systems, on the contrary, is complicated by low values of vapour pressure over indium and gallium chalcogenides and the complex composition of the vapour. For such systems the auxiliary component method was developed. The possibilities of its application are wide and are not limited to $\mathrm{A}^{\mathrm{III}} \mathrm{B}^{\mathrm{VI}}$ compounds. A new method for nonstoichiometry regulation was developed and applied using non-destructive selective chemical transport reactions (i.e. with the participation of an auxiliary component). This method is based on the introduction or removal of one of the sample components by means of a selective chemical transport reaction. In conclusion, the development of methods for the research and synthesis of intermediate phases with variable compositions (properties) was analysed based on the example of the discussed systems.

Keywords: Phase equilibria, Tensimetric methods, $\mathrm{A}^{\mathrm{IV}} \mathrm{B}^{\mathrm{V}}$ compounds, Indium and gallium chalcogenides, Phase diagrams For citation: G. V. Semenova, A. Yu. Zavrazhnov The development of methods for the research and synthesis of solid phases by the scientific school of Ya. A Ugai. Review. Kondensirovannye sredy i mezhfaznye granitsy= Condensed Matter and Interphases. 2021;23(3): 353-373. https://doi.org/10.17308/kcmf.2021.23/3526

Для цитирования: Семенова Г. В., Завражнов А. Ю. Развитие методов исследования и синтеза твердых фаз в научной школе Я. А. Угая. Обзор. Конденсированные среды и межфазные границы. 2021;23(3): 353-373. https://doi.org/10.17308/ kcmf.2021.23/3526

Galina V. Semenova, e-mail: semenova@chem.vsu.ru

(c) G. V. Semenova, A. Yu. Zavrazhnov, 2021 


\section{Introduction}

In 1981, Yakov Ugai was awarded with the USSR National Prize in Science and Technology for a series of studies in the area of chemical thermodynamics of semiconductors. This event honoured the contributions of the Voronezh school of inorganic chemists founded by him in the development of a new direction, semiconductor chemistry [1]. It was at Voronezh State University that Ya. A. Ugai established the country's first department of semiconductor chemistry and works aimed at the search for new materials and the study of their properties were conducted. Unique experimental units created by the department staff allowed exploring the nature of phase equilibria in complex systems with volatile components (phosphorus, arsenic, and sulphur) and to construct phase diagrams for such systems. Until now, some of these data are still unique and are quoted in international handbooks $[2,3]$. The contribution of Yakov A. Ugai identified research areas in the field of physics and chemistry for obtaining solid-phase materials.

\section{Phase equilibria in systems based on elements of groups IV and V in the periodic system}

The research into $\mathrm{A}^{\mathrm{IV}} \mathrm{B}^{\mathrm{V}}$ compounds hold an important place among the studies dedicated to the nature of phase equilibria in binary systems with volatile components carried out under the leadership of Ya. A. Ugai. Unlike the commonly known classes of $\mathrm{A}^{\mathrm{III}} \mathrm{B}^{\mathrm{V}}, \mathrm{A}^{\mathrm{II}} \mathrm{B}^{\mathrm{VI}}$, and $\mathrm{A}^{\mathrm{I}} \mathrm{B}^{\mathrm{VII}}$ compounds, these compounds belong to the class of so called abnormally constructed phases. They are formed by elements located in adjacent groups of the periodic system, which are largely similar in their physical and chemical nature. Owing to the special nature of the cationcation and anion-anion bonds in silicon and germanium phosphides and arsenides (as well as in indium and gallium monochalcogenides, which will be discussed in the second part of the article), they have highly specific properties. Silicon and germanium pnictogenides are semiconductors and have interesting optical and electrical properties [4,5]. However, there was clearly insufficient interest in this group of compounds due to the difficulty in synthesising high-quality crystals and a lack of information about phase diagrams which largely determine the set of production methods.

Owing to many years of research by the closest disciple and colleague of Ya. A. Ugai, Evgeny G. Goncharov, and other staff, this interesting class of compounds was finally characterised. They studied the properties of silicon and germanium phosphides and arsenides and constructed phase diagrams of the respective systems. It was shown that $\mathrm{Si}-\mathrm{As}$ and $\mathrm{Ge}-\mathrm{As}$ systems are characterised by two intermediate phases with the $A B$ and $A_{2}$ composition. Additionally, germanium arsenides and silicon monoarsenide melt congruently, and $\mathrm{SiAs}_{2}$ decomposes by a peritectic reaction [6-9]. It was revealed that the $\mathrm{Si}-\mathrm{P}$ system has two intermediate phases of phosphide and silicon diphosphide which melt congruently $[10,11]$, while the germanium-phosphorus system is characterised by a single intermediate phase of $\mathrm{GeP}$ which decomposes by a peritectic reaction [12-14]. It should be noted that such studies were made possible owing to a variety of techniques developed by the authors. They include using steel counter pressure chambers for the synthesis of samples, graphitisation of quartz ampoules, the introduction of an indifferent solvent and a number of other methods that distinguished the Voronezh school.

For the neighbouring elements in the periodic system the electronegativity values are close enough, and this factor does not play a major role. In this case, the peculiarities of component interactions are largely determined by the size factor. Hence the higher stability of silicon phosphides, the congruent nature of melting of silicon and germanium phosphides and arsenides, and the appearance of decomposing phases in $\mathrm{Si}-\mathrm{As}, \mathrm{Ge}-\mathrm{P}$ systems. This is also reflected in the nature of the formation of defects in these phases, which is characterised by the dominant role of antistructural defects (e.g., $\mathrm{Ge}_{\mathrm{As}}^{\prime}$ and $\mathrm{As}_{\mathrm{Ge}}^{-}$ in the Ge - As system) [15-19]. The study of the processes leading to the formation of defects enabled the electrophysical properties of these materials to be explained [20,21]. These studies led to the development of a platform for obtaining high-quality crystals with reproducible properties.

The studies of $\mathrm{A}^{\mathrm{IV}} \mathrm{B}^{\mathrm{V}}$ compounds were continued with the research of systems involving another element of the fourth group, tin. The 
data on phase equilibria in these systems are actually based on a few studies, mostly relating to compositions rich in tin. The data on vapour pressure of volatile components in these systems are extremely scarce and controversial. On the other hand, in recent years, there have been a large number of publications dedicated to tin phosphides used as negative electrode materials for lithium-ion batteries and for the creation of thermoelectric materials [22-33].

Three intermediate phases were detected in the $\mathrm{Sn}$ - P system: $\mathrm{Sn}_{4} \mathrm{P}_{3}$ decomposes at $823 \mathrm{~K}$ into two liquids of different compositions with a content of phosphorus of 22.5 and $47.0 \mathrm{~mol} \%$; $\mathrm{Sn}_{3} \mathrm{P}_{4}$ phase melts without decomposition at $833 \mathrm{~K}$, and $\mathrm{SnP}_{3}$ also decomposes by a synthetic schema. However, no specific experimental data have been provided [2]. It should be noted that the reference information on the phase equilibria in the Sn-P system is mainly based on one study [34]. In their research, the authors used visual polythermal method, which cannot fully evaluate the complex physical and chemical nature of the phases. $\mathrm{Sn}_{4} \mathrm{P}_{3}, \mathrm{Sn}_{3} \mathrm{P}_{4}, \mathrm{SnP}_{3}$ phases have a similar crystal structure with the $\mathrm{R} \overline{3} \mathrm{~m}$ space group similar to the structure of elements in the arsenic subgroup. This fact, together with the high reactivity and volatility of phosphorus, challenges the production of tin phosphides: due to similar atom coordination, a transition from one phase to another is possible even under slight changes in the conditions of synthesis. It was repeatedly mentioned that it was difficult to form the $\mathrm{Sn}_{3} \mathrm{P}_{4}$ phase. Despite the variation of the synthesis conditions, the resulting sample often contained $\mathrm{Sn}_{4} \mathrm{P}_{3}$ impurities. They only managed to produce the $\mathrm{Sn}_{3} \mathrm{P}_{4}$ compound as a result of the prolonged low-temperature annealing of stoichiometric amounts of tin and phosphorus.

The study of the Sn - P system by X-ray diffraction, differential thermal analysis, SEM, and EPXMA showed that within the concentration range of $43-70 \mathrm{~mol} \%$ of $\mathrm{P}$ there is only one invariant equilibrium with the participation of the higher phosphide of $\mathrm{L}_{2} \leftrightarrow \mathrm{Sn}_{4} \mathrm{P}_{3}+\mathrm{SnP}_{3}$ [35-38]. The temperature of the eutectic horizontal was determined to be $824 \mathrm{~K}$. As a result of prolonged annealing of alloys at temperatures below $673 \mathrm{~K}$, the alloys with the content of phosphorus of 43-57 mol\% were heterophasic mixtures of the
$\mathrm{Sn}_{4} \mathrm{P}_{3}$ and $\mathrm{Sn}_{3} \mathrm{P}_{4}$ phosphides and $\mathrm{Sn}_{3} \mathrm{P}_{4}$ and $\mathrm{SnP}_{3}$ were the samples with the greatest content of phosphorus. On the contrary, if the $\mathrm{Sn}_{3} \mathrm{P}_{4}$ phase was initially recorded in the samples, the hightemperature annealing at a temperature of 773 $\mathrm{K}$ led to its decomposition into the adjacent phases of $\mathrm{Sn}_{4} \mathrm{P}_{3}$ and $\mathrm{SnP}_{3}$. In particular, the $\mathrm{Sn}_{3} \mathrm{P}_{4}$ sample, produced as a result of two-temperature synthesis, decomposed completely under such heat treatment. Thus, a conclusion was made about the peritectoid decomposition of the $\mathrm{Sn}_{3} \mathrm{P}_{4}$ phosphide. The use of high-temperature in situ spectrophotometry of saturated phosphorus vapour over alloys of the $\mathrm{Sn}-\mathrm{P}$ system allowed estimating the concentration of this component in the vapour and calculating the pressure value. For the first time, the $P-T-x$ diagram was constructed (Fig. 1) [39-41].

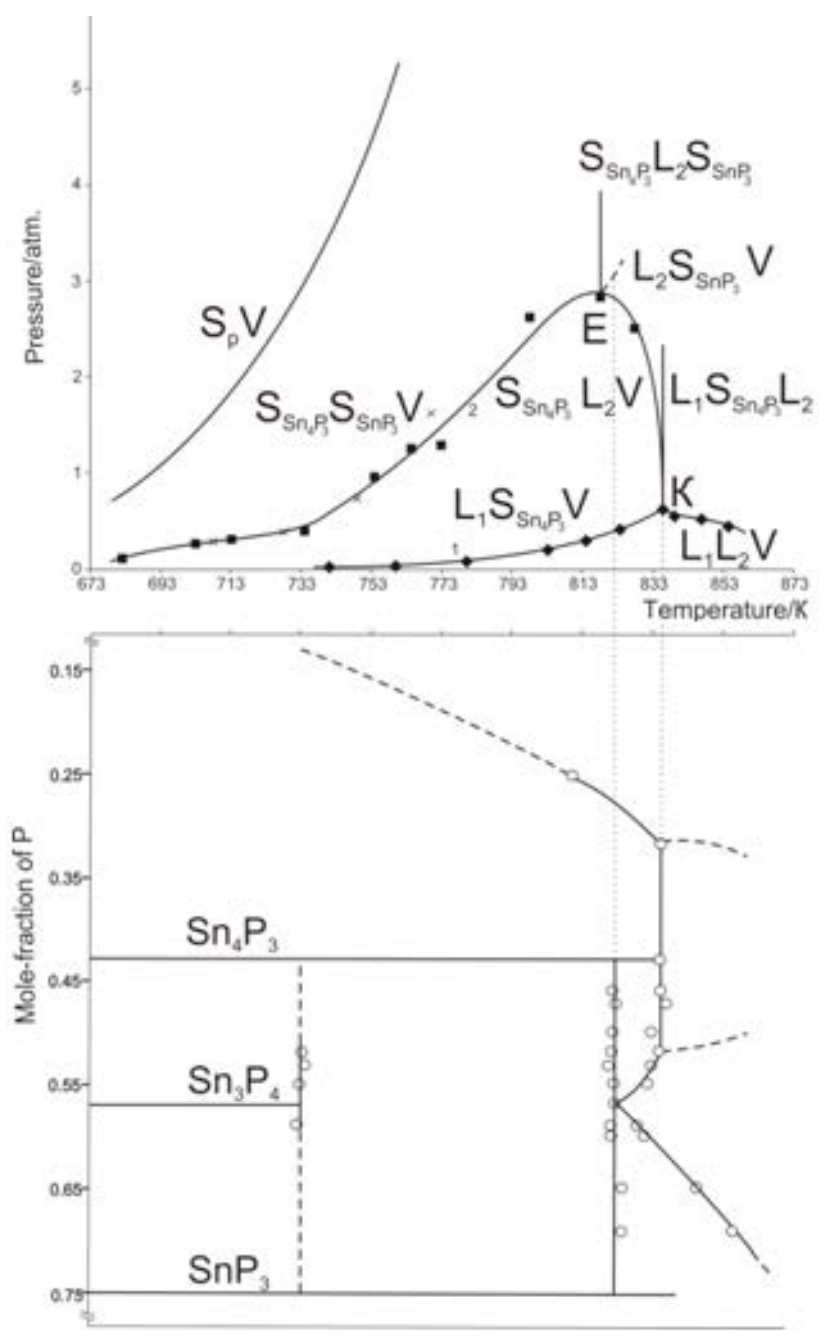

Fig. 1. $P-T-x$ diagram of the Sn-P: (a) $P-T$; (b) $T-x$ projection 
Silicon and germanium phosphides and arsenides were used as solid phase diffusants upon the doping of elemental semiconductors. These compounds are of great practical value for two reasons: their anisotropic electrophysical characteristics resulting from the low-symmetry structure; and their layered crystal structure which allows for the intercalation of ions and molecules into the interlayer space. However, despite the obtained physical and chemical information about the $\mathrm{A}^{\mathrm{IV}} \mathrm{B}^{\mathrm{V}}$ compounds, their application as semiconductor materials did not become widespread.

The discovery of graphene provoked a considerable interest in 2D semiconductor materials [42-46]. From this point of view, using the $\mathrm{A}^{\mathrm{IV}} \mathrm{B}^{\mathrm{V}}$ compounds characterised by a layered structure with weak van der Waals bonds between the layers, is promising. The presence of volatile components makes it challenging to synthesise such compounds, which is why [42] attempted to obtain 2D samples of silicon phosphide in the presence of bismuth or tin. In the latter case, Sndoped materials with peculiar semiconductor properties were obtained. However, the lack of information about the phase equilibria in the $\mathrm{A}^{\mathrm{IV}}-\mathrm{B}^{\mathrm{V}}-\mathrm{Bi}$ and $\mathrm{A}^{\mathrm{IV}}-\mathrm{B}^{\mathrm{V}}-\mathrm{Sn}$ ternary systems makes further research in this area rather problematic.

Phase diagrams were built for the $\mathrm{Bi}-\mathrm{GeAs}_{2}$ and $\mathrm{Bi}-\mathrm{GeAs}$ polythermal cross sections of the $\mathrm{Ge}-\mathrm{As}-\mathrm{Bi}$ system [47]. It was established that in the ternary system there was a $\mathrm{L} \leftrightarrow \mathrm{GeAs}+\mathrm{Bi}+\mathrm{Ge}$ eutectic and a $\mathrm{L}+\mathrm{GeAs}_{2} \leftrightarrow \mathrm{GeAs}+\mathrm{Bi}$ peritectic four-phase transformations which occurred at a temperature of 542 and $548 \mathrm{~K}$, respectively. It was shown that the four-phase processes in the ternary system occurred in the areas of concentrations with a high content of bismuth. Therefore, bismuth may be used as an indifferent solvent. However, due to the flat shape of the liquidus surface, a great amount of its additions is required to reduce the temperature of the alloy synthesis.

The nature of the phase diagram of the $\mathrm{Sn}-\mathrm{As}-$ Ge system is more complex [48-52]. Fig. 2 shows a topological equilibrium diagram that illustrates phase transformations and successive (with decreasing temperature) crystallisation processes in the Ge-As-Sn system. The polythermal cross sections SnAs - GeAs and SnAs - GeAs ${ }_{2}$ can perform phase subsolidus demarcation of the state diagram of the Sn - As - Ge system. However, they are not quasibinary. There are also non-variant peritectic equilibria $\mathrm{L}+\mathrm{GeAs}_{2} \leftrightarrow \mathrm{GeAs}+\mathrm{SnAs}$ $(838 \mathrm{~K})$ and $\mathrm{L}+\mathrm{As} \leftrightarrow \mathrm{SnAs}+\mathrm{GeAs}_{2}(843 \mathrm{~K})$ in the system. Comparing the form of the polythermal cross sections of Sn-GeAs [49] and Bi-GeAs [47], it can be concluded that even small additions of tin significantly soften the conditions for obtaining germanium arsenide, however, the possibility of a $\mathrm{Sn}_{4} \mathrm{As}_{3}$ auxiliary phase makes tin a less attractive solvent as compared to bismuth, which acts as an indifferent solvent over the entire concentration range.

The same type of bonds, similar crystalchemical structure, and favourable "size" factor determine a possibility to form a continuous series of solid solutions between $\mathrm{A}^{\mathrm{IV}} \mathrm{B}^{\mathrm{V}}$ compounds. In $[53,54]$, it was shown that the formation of solid solutions with cation substitution is extremely difficult. The formation of solid solutions between silicon and germanium phosphides and arsenides, in contrast, can be performed quite easily $[55,56]$. A feature of the directed synthesis of ternary solid solutions is the need to simultaneously control the composition by two parameters: such properties as bandgap, the lattice constant, etc. can be varied by altering the molarity of the solid solution; and the deviation from stoichiometry allows controlling the type and the concentration of the carriers. Therefore, there is a need in a comprehensive study of phase diagrams of the $\mathrm{A}^{\mathrm{IV}}$-As-P ternary systems which would include the analysis of defect formation processes in ternary solid solutions. This involves examining the nature of the interaction between the elements of group $\mathrm{V}$.

$P-T-x$ diagrams for the $\mathrm{Sb}-\mathrm{As}$ and $\mathrm{As}-\mathrm{P}$ systems were constructed with the help of a combination of differential thermal analysis and the static manometric method [57-62]. Due to very high values of saturated vapour pressure, it is extremely difficult to measure it directly along the three-phase equilibrium line. In [60], this problem was solved as follows. Lead was introduced into the system. It acted as an indifferent solvent which reduced the phase transition temperature. The authors measured the vapour pressure in liquidus points for sections with different quantities of lead and then extrapolated these values so that the content of lead was zero in the alloy with different 


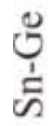
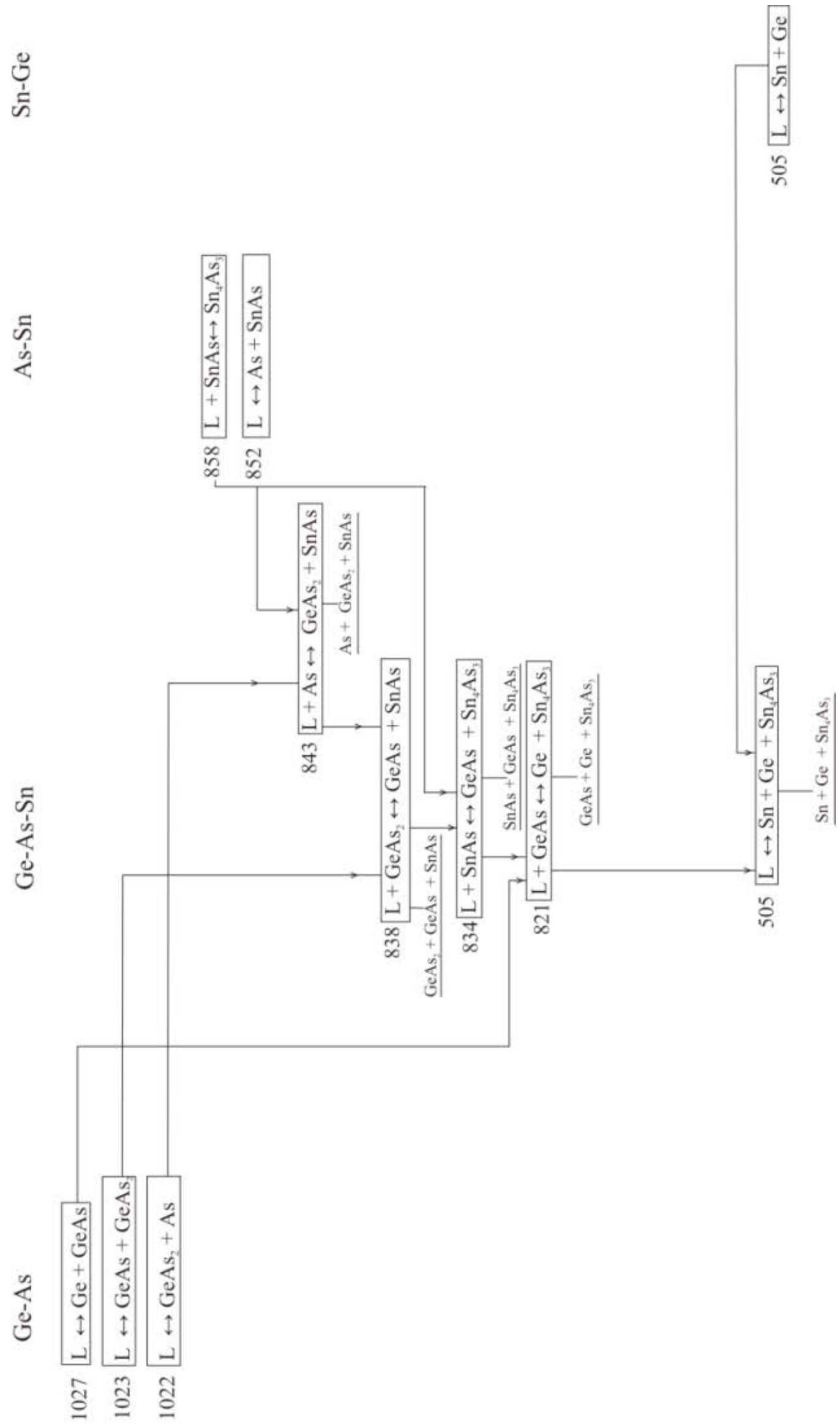
ratios of arsenic and phosphorus. This allowed establishing the coordinates of the three-phase equilibrium line in the $\mathrm{P}$-As system. According to these data, the system has an intermediate berthollide phase which melts with a peritectic reaction. However, the nature of this phase was not discussed and there was no information about the parameters of the crystal lattice. To support this version the authors of [60-62] provided data of a thermographic study, according to which $T-x$ diagram has two horizontals corresponding to invariant processes of the $\gamma$-phase formation from the arsenic-based melt and solid solution of $L+\beta \leftrightarrow \gamma$ and phosphorus-based $\alpha$-solid solutions: $L+\gamma \leftrightarrow \alpha$. This was also indicated by the results of tensimetric studies according to which groups of $P$ - $T$-curves that coincide within the experimental error tolerance can be distinguished. $P-x$ isotherms constructed at 773 , 823 , and $873 \mathrm{~K}$ confirmed the presence of two heterophase areas in the $\mathrm{P}-$ As system.

There is another version regarding the nature of the phase equilibria, according to which the $\mathrm{P}$ - As system has limited solid solutions based on the components, however, the specific feature of the experiment was that alloys were prepared in the presence of metallic mercury [63, 64]. This contributed to the transition of phosphorus into its orthorhombic modification (black phosphorus). In fact, the experiment described phase relations under completely different conditions.

Recently, a huge interest in layered structures, and the orthorhombic modification of phosphorus in particular, has provided new results in the study of pnictogens and systems formed by them [65-68]. For example, [69] described an attempt to obtain orthorhombic modifications of phosphorus and arsenic under conditions close to normal. It showed the mutual influence of arsenic and phosphorus on the possibility to form different allotropes. On the one hand, arsenic promotes the crystallisation of amorphous red phosphorus. On the other hand, it promotes the formation of the orthorhombic modification even in the absence of catalysts of the process (e.g. mercury or $\mathrm{PbI}_{2}$ ). The sample with the $\mathrm{As}_{0.7} \mathrm{P}_{0.3}$ composition was prepared by heating the amorphous red phosphorus and grey (rhombohedral) arsenic. Tensimetric studies showed that at $723 \mathrm{~K}$ phosphorus crystallises to its violet modification (Hittorf's phosphorus).
Both phases are metastable, since their pressures are higher than the pressure of black phosphorus vapour. At $773 \mathrm{~K}$, the pressure drops and an orthorhombic modification is formed, i.e. solid solution of arsenic and phosphorus. Using the results of the X-ray diffraction analysis of the samples of the P - As system, we established that at concentrations of $55-85 \mathrm{~mol} \%$ of As there is a heterophasic mixture of a solid solution of phosphorus in $\alpha$-As and a phase with an orthorhombic crystal lattice with the parameters of $a=3.48, b=4.42, c=10.81 \mathrm{~A}$. Therefore, the phase with a structure identical to that of black phosphorus is formed in the $\mathrm{P}$ - As system without the addition of catalysts or the use of high pressure. The nature of the phase relations in the P - As system requires further research.

The analysis based on the experimental studies of a number of polythermal cross sections of phase diagrams of the $\mathrm{Ge}-\mathrm{As}-\mathrm{P}, \mathrm{Si}-\mathrm{As}-\mathrm{P}$ ternary systems [70-75] showed that in case of anionic substitution solid solutions are formed without any notable difficulties. Solid solutions are formed in the GeAs - GeP system over the entire range of concentrations, whereas in the $\mathrm{Si}$ - As - P ternary system there is a peritectic mixture of silicon phosphide and arsenidebased solid solutions and the heterogeneous region extends from 45 to $60 \mathrm{~mol} \%$ of SiP at $1300 \mathrm{~K}$. To obtain crystals of solid solutions homogeneous along the length of the ingot in the $\mathrm{Ge}-\mathrm{As}$ - P system, it was proposed to use the method of two-temperature synthesis followed by directed crystallisation of the melt and to use As - P melts as a source of volatile components. Using alloys which are a heterophasic mixture of the intermediate $\gamma-\mathrm{As}_{1-x} \mathrm{P}_{x}(x=0.3 \div 0.4)$ and a phosphorus or arsenic-based solid solution allows growing homogeneous crystals of solid solutions under the conditions of controlled vapour pressure of the two volatile components. The composition of the resulting $\mathrm{GeAs}_{1-x} \mathrm{P}_{x}$ solid solutions can be varied by changing the temperature of the source zone [70].

The investigation of phase equilibria in the $\mathrm{Sn}-\mathrm{As}-\mathrm{P}$ system is challenging, not only due to difficulties of working with volatile components, phosphorus and arsenic, but also to a large number of intermediate phases. In such complex systems, triangulation is normally conducted 
and it is divided into simpler individual systems, but in this case it is not possible because of the wide regions of solid solutions, based both on individual components and on intermediate phases. In this case, we can talk about phase subsolidus demarcation.

The study of the Sn - As - P systems in the regions of high tin concentrations established a continuous series of solid solutions between arsenide and phosphide with the composition of $\mathrm{Sn}_{4} \mathrm{~B}_{3}(\alpha$-solid solutions) [76].

$\mathrm{X}$-ray diffraction analysis of the alloys whose compositions belong to the polythermal cross sections of $\mathrm{SnAs}-\mathrm{Sn}_{0.43} \mathrm{P}_{0.57}, \mathrm{Sn}_{4} \mathrm{As}_{3}-\mathrm{Sn}_{0.43} \mathrm{P}_{0.57}$, and $\mathrm{SnAs}-\mathrm{Sn}_{0.5} \mathrm{P}_{0.5}$ revealed that in addition to the $\alpha$-phase the samples have solid solutions based on tin monoarsenide and tin phosphide $\mathrm{SnP}_{3}[77,78]$. The formation of solid solutions based on tin monoarsenide ( $\beta$-solid solutions) is indicated by a shift of the characteristic lines of the SnAs spectra toward greater angles. What is more, the shift increases with an increase in the molar fraction of phosphorus. In contrast, the alloys of the investigated polythermal cross sections with a content of phosphorus of more than $70 \mathrm{~mol} \%$ for the $\mathrm{SnP}_{3}$ reflexes demonstrate a natural increase in the interplanar spaces which indicates the replacement of phosphorus atoms with arsenic atoms whose radius is greater. Solid solutions based on $\mathrm{SnP}_{3}$ tin phosphide $(\gamma$-solid solutions) are formed [79].

The study of the SnAs-SnP ${ }_{3}$ polythermal cross section in the Sn-As-P ternary system by X-ray diffraction analysis revealed that the region of solid phase solubility based on tin monoarsenide extends up to $30 \mathrm{~mol} \%$ of $\mathrm{SnP}_{3}$ [80]. The analysis of the obtained data in combination with the results of the study of alloys with lower tin contents allowed establishing the presence of four-phase equilibria of the peritectic type with the participation of the melt and solid solutions based on tin monoarsenide, tin phosphide $\mathrm{SnP}_{3}$, and the $\mathrm{As}_{0.6-0.7} \mathrm{P}_{0.4-0.3}$ intermediate phase. It was found that in the region of the $\mathrm{Sn}-\mathrm{As}-\mathrm{P}$ phase diagram with the tin content below 50 mol\% in addition to four-phase equilibria $L \leftrightarrow \alpha+\beta+\gamma$ $(818 \mathrm{~K})$ at a temperature of $824 \mathrm{~K}$ there is an invariant equilibrium of the peritectic type with the participation of solid solutions based on tin monoarsenide, tin phosphide $\mathrm{SnP}_{3}$, and the intermediate $\delta$-phase $\mathrm{As}_{1-x} \mathrm{P}_{x}: \mathrm{L}+\delta \leftrightarrow \beta+\gamma($ Fig. 3).

We would like to draw attention to the fact that a deep understanding of the processes occurring in multicomponent systems is impossible without the development of methods of phase diagrams construction and determining

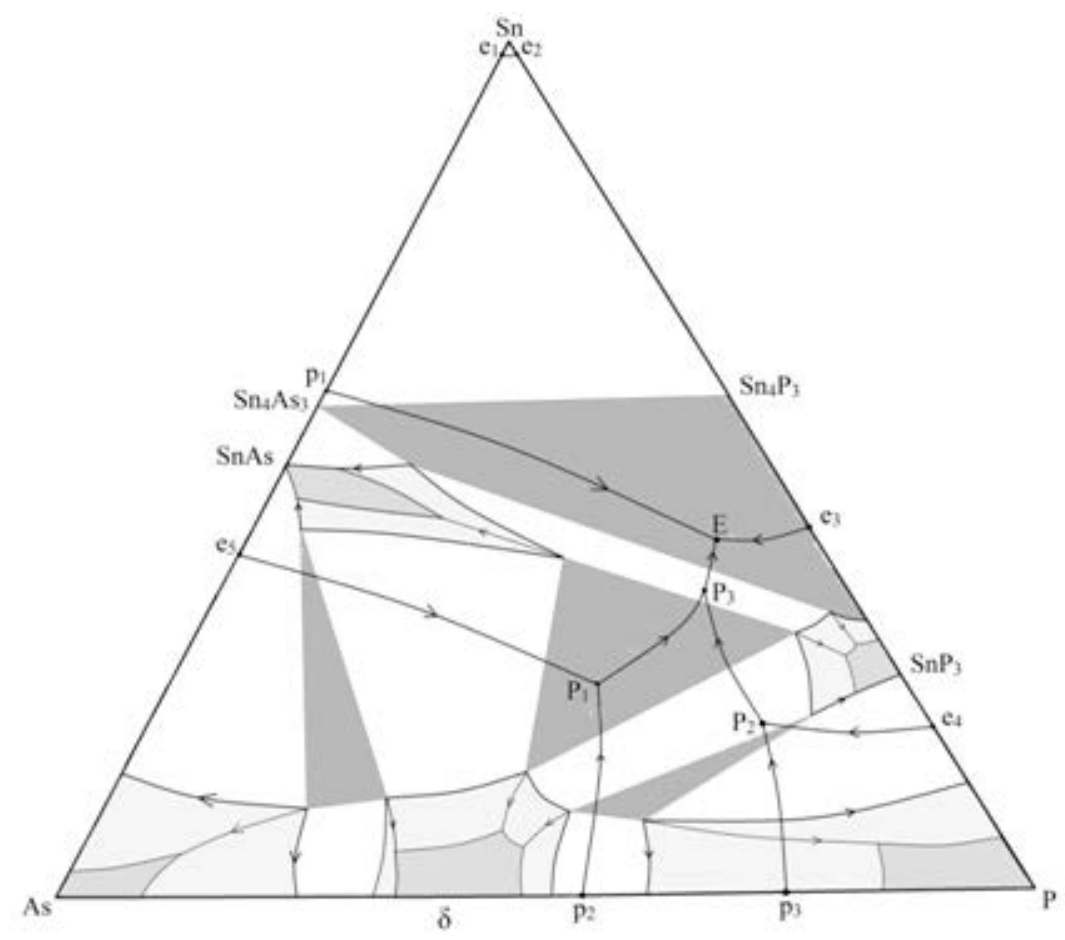

Fig. 3. Scheme of phase equilibria in the Sn-As- P system 
regions of condensed phases. Tensimetric (and in particular, manometric) methods which study the dependence of pressure on temperature or composition of condensed phases equilibrium with vapour are considered to be the most direct and appropriate methods to solve such tasks.

It should be noted that $P T x$ diagrams of the $\mathrm{Ge}-\mathrm{As}, \mathrm{Si}-\mathrm{As}, \mathrm{Ge}-\mathrm{P}$, and $\mathrm{Si}-\mathrm{As}$ binary systems and the $\mathrm{A}^{\mathrm{IV}}-\mathrm{B}^{\mathrm{V}}-\mathrm{C}^{\mathrm{V}}$ ternary systems were defined with the help of manometric tensimetry, i.e. using a quartz null-manometer with a flat membrane [6 -18]. These studies were greatly facilitated due to the absolutely incongruent nature of silicon and germanium phosphides and arsenides evaporation (sublimation), wherein only phosphorus or arsenic transit to the vapour phase mainly in the form four-atom molecules. Definite vapour composition allowed the composition of the equilibrium condensed matter to be reliably and easily determined at known values of temperature $(T)$, pressure $(P)$, the volume of the reaction chamber $(V)$, and the initial amounts of components used to prepare the sample of silicon or germanium phosphides or arsenides $\left(n^{\circ} \mathrm{A}^{\mathrm{IV}}\right),\left(n^{\circ} \mathrm{B}^{\mathrm{V}}\right)$.

The results of tensimetric experiments allowed not only defining a set of intermediate phases in the $\mathrm{A}^{\mathrm{IV}}-\mathrm{B}^{\mathrm{V}}$ systems but also establishing unusual variation of homogeneity ranges of germanium and silicon diarsenides with temperature changes [18]. The authors [18] associated this feature with autointercalation of $\mathrm{SiAs}_{2}$ and $\mathrm{GeAs}_{2}$ by arsenic at premelting temperatures. In the transfer to the $\mathrm{A}^{\mathrm{IV}}-\mathrm{B}^{\mathrm{V}}-\mathrm{C}^{\mathrm{V}}$ ternary systems it was still possible to calculate the composition of vapour and solid phases despite a more complex vapour composition due to the formation of mixed molecules of $\mathrm{P}_{x} \mathrm{As}_{4-x}$ in the vapour.

The next stage was to validate the identified peculiarities of silicon and germanium phosphides and arsenides using the compounds of $\mathrm{A}^{\mathrm{III}} \mathrm{B}^{\mathrm{VI}}$, indium and gallium monochalcogenides. These compounds are $\mathrm{A}^{\mathrm{IV}} \mathrm{B}^{\mathrm{V}}$ isoelectronic phases. They are similar to them in the structure and nature of chemical bonds. Also, similar to $\mathrm{A}^{\mathrm{IV}} \mathrm{B}^{\mathrm{V}}$ compounds, the practical application of $\mathrm{A}^{\mathrm{III}} \mathrm{B}^{\mathrm{VI}}$ compounds is experiencing a surge of interest. Basically, this interest is related directly to graphitelike quasi-2D-structure of indium and gallium monochalcogenides [81-84]. Of no less interest is the application of sesquichalcogenides (of type
$\mathrm{Ga}_{2} \mathrm{~S}_{3}$ ), structures with a great concentration of stoichiometric vacancies in the cation sublattice (up to $1 / 3$ of the number of nodes) [85]. However, the phase diagrams of the $\mathrm{A}^{\mathrm{III}}-\mathrm{B}^{\mathrm{VI}}$ systems need to be detailed. The study of these systems is complicated by low values of vapour pressure over indium and gallium chalcogenides and the complex composition of the vapour, which makes it impossible to use classical manometric methods.

For this reason, the auxiliary component method (AC) was developed for systems with unsuitable (generally very small for the experiment) values of vapour pressure. It should be noted that the possibilities regarding the application of this method are quite wide and are not limited to the $\mathrm{A}^{\mathrm{III}} \mathrm{B}^{\mathrm{VI}}$ compounds for which it was originally designed.

\section{A new method for studying phase diagrams and phase equilibria: the auxiliary component method}

The idea of the method is to bypass equilibrium (1) between the $X$ component, which was a part of the $X_{n} Y_{m}$ condensed phase, and its vapour

$X^{\prime \prime} \rightarrow X^{\prime}$

and to create a suitable for the study equilibrium with an auxiliary component additionally introduced into the system. For example,

$X^{\prime \prime}+q Z \underset{\leftarrow}{\rightarrow} X Z_{q}$,

where $Z$ is the auxiliary component, and at least one of the $Z$ and $X Z_{q}$ substances has to be volatile and form a vapour. In equations (1), (2) and hereinafter, the symbol "'"” corresponds to the component in the condensed state, and the symbol "'" corresponds to the component in the state of vapour.

The principles of this approach have been used in the past. There are several works in the literature, where a number of oxide or sulphide systems was studied with the help of hydrogen or carbon $(X=\mathrm{O}$ or $\mathrm{S}, Z=\mathrm{H}_{2}$ or $\mathrm{C}^{\text {<raphite> }}$, volatile forms of $X Z_{q}-\mathrm{H}_{2} \mathrm{O}$, $\mathrm{H}_{2} \mathrm{~S}$ or $\mathrm{CS}_{2}$ ). However, there has been no systematic research in this area and the possibilities of the AC method have not been thoroughly studied.

First of all, let us analyse various possibilities of the auxiliary component method. The results of this analysis can be used for the selection of the optimal strategy to solve research objectives 
and directed synthesis of new inorganic materials with a set composition, and, consequently, with set properties.

\subsection{The role of the auxiliary component (AC)} vapour in tasks aimed at the study of phase diagrams. The $K_{P}^{\#}$ value and its informative value. The indicating function of the AC

Our analysis only considered the situation when the auxiliary component was only present in vapour and condensed phases belonged to a binary system. Obviously, when $Z$ substance is made to contact the $X_{n} Y_{m}$ condensed phase, the number of components in the system will increase by one. However, approaching the complete insolubility of the $Z$ component in the studied condensed phases, a subsystem can be singled out which only contains studied phases with the original components. Relative to this subsystem, its remaining part with the auxiliary component will play the role of an external body. The latter, in addition to other properties, is an indicator of the state of the studied phases. In particular, the indicator vapour phase allows "reading" condensed phase information about chemical potentials of their constituent components. For example, when investigating low-volatile inorganic sulphides by means of hydrogen, there is the equilibrium

$\mathrm{S}^{\prime \prime}+\mathrm{H}_{2}^{\prime} \underset{\leftarrow}{\leftarrow} \mathrm{H}_{2} \mathrm{~S}^{\prime}$,

for which the necessary equilibrium conditions

$\mu_{\mathrm{S}}^{\prime \prime}+\mu_{\mathrm{H} 2}^{\prime}-\mu_{\mathrm{H} 2 \mathrm{~S}}^{\prime}=0$,

give

$\mu_{\mathrm{s}}^{\prime \prime}=R T \ln K_{P}^{\#}+F$,

where in (4) and (5), $\mu_{\mathrm{s}}^{\prime \prime}$ are chemical potentials of bound sulphur in sulphide, $\mu_{\mathrm{H}_{2}}^{\prime}$ and $\mu_{\mathrm{H}_{2} \mathrm{~S}}^{\prime}$ are chemical potentials of hydrogen and hydrogen sulphide in the vapour, $K_{p}^{\#}$ is the value, which is often called the constant of heterogeneous equilibrium, and the element $F$, which only depends on the temperature, represents the difference between standard chemical potentials of molecular forms of gas:

$F=\mu_{\mathrm{H} 2 \mathrm{~S}}^{\prime \circ}-\mu_{\mathrm{H}_{2}}^{\prime \circ}$.

The $K_{p}^{\sharp}$ value connects the partial pressures of gases as

$K_{P}^{\#}=\frac{p_{\mathrm{H}_{2} \mathrm{~S}}}{p_{\mathrm{H}_{2}}}$,
Since $K_{p}^{\#}$, according to (5), depends both on temperature and composition and slightly on pressure, it would be more correct to call it pseudoconstant of heterogeneous equilibrium. We will show below that $K_{P}^{\sharp}$ is a convenient experimental value. Equation (5) is also valid for a more general case of (2), naturally the respective components in the above expression need to be replaced.

\subsection{The possibility to obtain and study such} conditions of condensed phases in which these phases cannot coexist with their own vapours. The contractive function of the $A C$

It is important to note that in contrast to the equilibrium "condensed phase - its own saturated vapour", the equilibria with the participation of an auxiliary component will involve such states of condensed phases in which these phases do not coexist with their own vapours.

By "their own vapours" we understand such vapours that are present in heterogeneous equilibria without the participation of an auxiliary component.

For example, carbon placed in a closed and initially evacuated system with free volume will give way to the equilibrium "graphite - carbon vapour" (it is obvious that the last phase at temperatures below $2000{ }^{\circ} \mathrm{C}$ will be extremely sparse). However, diamond can never act as a condensed phase in such equilibrium since in the phase diagram of a single-component system diamond at any temperatures does not coexists with the vapour in the subcritical region. However, a gas consisting of carbon oxides may well coexist with diamond in the equilibrium at sufficiently high pressures

$\mathrm{C}^{\text {diamond }}+\mathrm{CO}_{2}^{\prime} \underset{\leftarrow}{\longrightarrow} 2 \mathrm{CO}^{\prime}$

In this case, vapour with an auxiliary component plays an important role and acts both as the indicator phase and the contractive medium.

For such problems, as far as it is actually known by the authors of this work, the auxiliary component method has not been used yet. It should also be noted that almost all instrumental methods of investigation of solids are directly (classical tensimetric methods) or indirectly (electrophysical methods) associated with the investigation of phases in the region of their coexistence with their own vapour. On the contrary, for the study of solids 
in the regions where the coexistence with saturated vapour is not possible, there is a very limited number of methods. What is more, most of them are not very accurate (for example, the method of thermal electromotive force). Therefore, the considered approach may be useful, for example, for solid-state chemistry or high-pressure materials science.

If the dependence of the chemical potential of the condensed phase on the pressure is substantial, the correct construction of $T-x$-sections including a detailed description of the homogeneity ranges, is only possible with the help of the auxiliary component method. This statement is even true for such cases when the phase allows for the possibility of direct tensimetric measurements. The demand for such studies will be apparent if it is necessary, for example, to compare the range of homogeneity of a phase at very different pressures (for example, 1 and $10000 \mathrm{~atm}$ ).

3.3. The construction of phase diagrams of binary systems using an AC. Retrieving thermodynamic information. The amplifying function of the $A C$

Another area of application of the auxiliary component is ideologically opposite to the ap- proach described above. It is based on the thesis that chemical potentials of the condensed phase components are typically not very sensitive to pressure changes if they do not exceed hundreds or thousands of atmospheres. Then, the state of the condensed phase equilibrium with the vapour of the auxiliary component can be considered the same as in the equilibrium with its own saturated vapour. Applying this to equation (5) it can be expected that the temperature dependence of the $K_{p}^{\#}$ value for various compositions of condensed phases should be very close to the classical $p$-Tdiagram. For example, $[86,87]$ present the results of a null-manometer study of the phase diagram of the $\mathrm{Ga}-\mathrm{S}$ and $\mathrm{Ga}$ - Se systems using the equilibrium

$2 \mathrm{Ga}^{\prime \prime}+\mathrm{GaHal}_{3}^{\prime} \underset{\leftarrow}{\longrightarrow} 3 \mathrm{GaHal}^{\prime}(\mathrm{Hal}=\mathrm{Cl}, \mathrm{I})$,

$K_{P}^{\#}=\frac{p_{\mathrm{GaHal}}^{3}}{p_{\mathrm{GaHal} 3}}$.

In Fig.1, in the temperature dependence of the $K_{P}^{\#}$ value $\left(\mathrm{Ga}_{\text {(lig) }}-V\right.$, GaSe $-L_{\mathrm{Ga}}-V$, $\mathrm{GaSe}-\mathrm{Ga}_{2} \mathrm{Se}_{3}-V$ equilibrium) lines similar to lines of the monovariant equilibrium for the $p-T$ diagrams are clearly visible. As expected, the position of these lines does not depend on

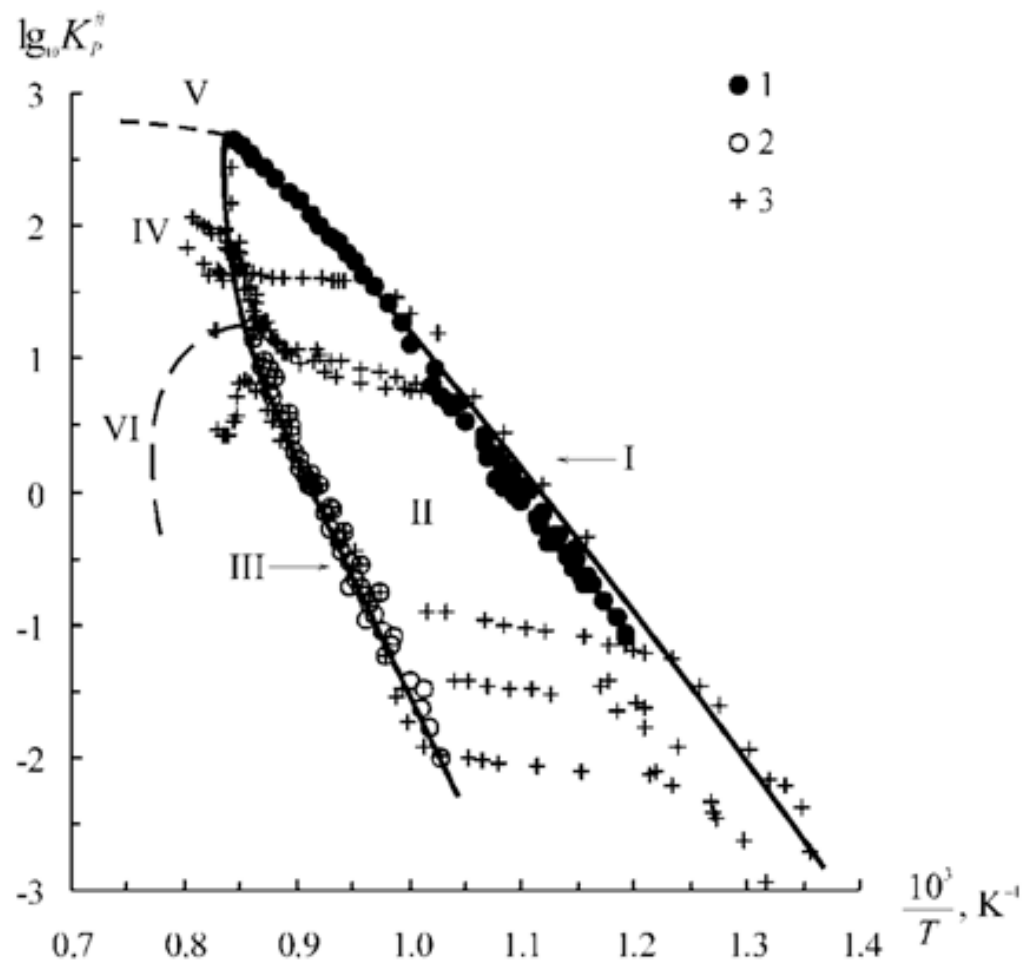

Fig. 4. The temperature dependence of the $K_{p}^{\sharp}$ value for heterogeneous equilibria of different natures: I - equilibrium line: $\mathrm{Ga}_{(\mathrm{l})}-\mathrm{GaSe}_{(\mathrm{s})}-V_{\mathrm{GaI}+\mathrm{Gal} 3}$; II - the GaSe $\mathrm{G}_{(\mathrm{s})} V_{\text {Gal }+\mathrm{Gal} 3}$ equilibrium region; III - the $\mathrm{GaSe}_{(\mathrm{s})}-\mathrm{Ga}_{2} \mathrm{Se}_{3(\mathrm{~s})}-V_{\text {GaI }+\mathrm{Gal} 3}$ equilibrium region; IV, V, VI - a schematic representation of the regions: IV - GaSe $e_{(s)} \mathrm{L}_{\text {Gase-based }}^{(s)}-V_{\text {Gal }+ \text { Gall }} ; \mathrm{V}-$ $L_{\text {Ga-based }} \mathrm{L}_{\text {Gase-based }} \mathrm{V}_{\text {GaI + Gal3 }} ; \mathrm{VI}-\mathrm{Ga}_{2} \mathrm{Se}_{3(s)} \mathrm{L}-\mathrm{V}_{\text {GaI + Gal3 }} ; 1-7$ - experimental curves in the area of equilibrium II 
the bulk composition of the GaSe alloy, on the weight of the sample, and the total pressure $P$ $\left(P \approx p_{\mathrm{GaI}}+p_{\mathrm{GaI} 3}\right.$; vapour unsaturated in relation to gallium iodides, pressure range: from 0.1 to $0.7 \mathrm{MPa})$. In [86, 87], it was also shown that the homogeneity range of the GaSe phase sharply expands and shifts toward selenium in a narrow temperature range (from $\sim 0.2 \mathrm{~mol} \%$ at $1100 \mathrm{~K}$ to $0.8 \mathrm{~mol} \%$ at $1180 \mathrm{~K}$ ). It also has a retrograde solidus for selenium.

Since the chemical potential of the condensed phase component is associated with the (pseudo) constant of the heterogeneous equilibrium $K_{P}^{\#}$, the analysis of the latter value as a function of the thermodynamic variables gives a lot of information not only about boundaries but also about the behaviour of the phase within its homogeneity range. For example, [8890] described the results of the study of the In - S system with the help of hydrogen. The dependence of the $K_{P}^{\#}$ value (see equilibrium 3 ) on the sulphur concentration for the $\operatorname{In}_{3-x} \mathrm{~S}_{4}$ phase at $T=$ const (Fig. 5) shows that the $\operatorname{In}_{3-x} \mathrm{~S}_{4}$ homogeneity range has a tendency to break up into separate phases with similar stoichiometry.

\subsection{Calculation of partial pressures and $p-T$ diagram}

The approach associated with the approximation regarding the negligible impact of pressure on the chemical potential of the condensed phase components can be applied to calculate $p-T$ diagrams of the original system under study. As a consequence of this approximation the introduction of the AC does not shift heterogeneous equilibria associated with self-sublimation of the components of the studied phase. In other words, the partial pressures of their own vapours in systems with an AC and without this component should not differ if the two systems are in the same conditions. Furthermore, the partial pressures may be calculated for known values of (pseudo) constant of the heterogeneous equilibrium $K_{P}^{\#}$. The details of such calculations are described in depth in $[87,88]$.

It should be noted that the determination of the partial pressure values allows comparing data obtained using different auxiliary components or comparing data of experiments with an $\mathrm{AC}$ with

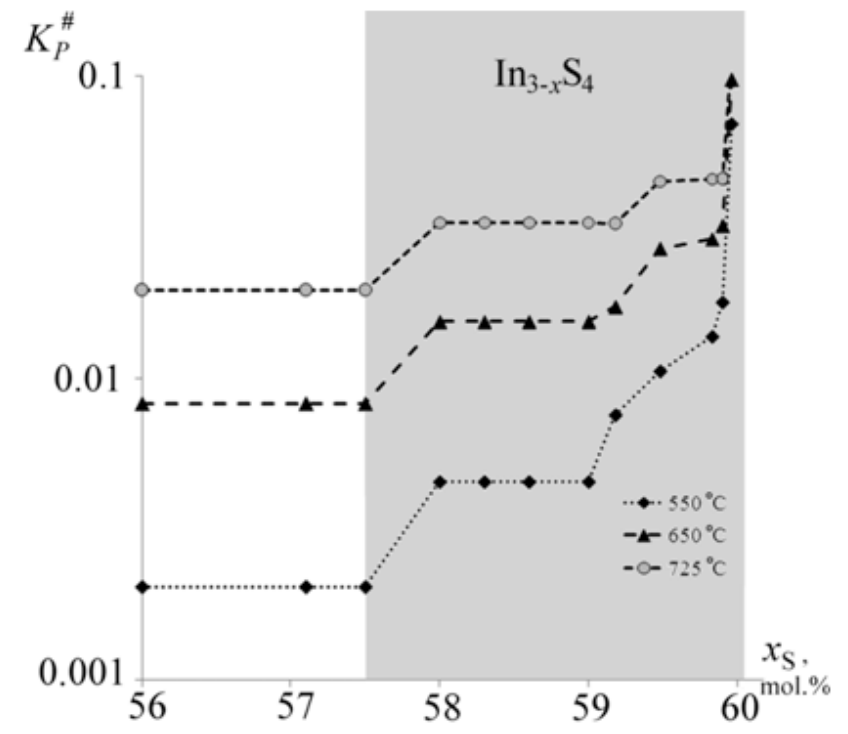

Fig. 5. Isotherms of the $K_{P}^{\#}$ dependencies of the sulphur content in the $\operatorname{In}_{3-x} \mathrm{~S}_{4}$ phase. The $K_{P}^{\#}$ value refers to the $\mathrm{S}^{\prime \prime}+\mathrm{H}_{2}{ }^{\prime}=\mathrm{H}_{2} \mathrm{~S}^{\prime}$ equilibrium where $\mathrm{S}^{\prime \prime}$ refers to the sulphur chemically bound in condensed phases of the In - S system

the results of direct study (for example, mass spectrometry). Thus, in the above-mentioned work [87], practically identical results for the pressure of gallium vapour over gallium selenides were obtained using iodine and chlorine (in the form of $\mathrm{GaI}_{3}$ and $\mathrm{GaCl}_{3}$ ) as auxiliary components. It should also be noted that the calculated pressures may be so small that they cannot even be determined by mass spectrometry. For example, the partial pressure of gallium vapours for the $\mathrm{GaSe}-\mathrm{Ga}_{2} \mathrm{Se}_{3}-V$ equilibrium calculated at a temperature of $700 \mathrm{~K}$ is $1.7 \cdot 10^{10} \mathrm{~Pa}$ [87]. In such cases, we can say that the auxiliary component plays the role of an amplifier of the signal sent to the external device by a very small value of the partial pressure of a low-volatile component.

\subsection{Possibility to calculate thermodynamic quantities}

In the case of independent experimental determination (up to a certain constant) of chemical potential of the second component $\left(\mu_{Y}\right)$ of the $X_{m} Y_{n}$ phase, the value $K_{P}^{\#}$ allows finding the molar Gibbs energy of the formation of this phase $\left(\Delta_{\mathrm{f}} G\right)$. If it is impossible to experimentally determine the potential of the second component, the value of the Gibbs energy may be determined by the Gibbs-Duhem equation. Further, the $\Delta_{\mathrm{f}} G$ 
data will allow calculating other molar properties: entropy, enthalpy, volume, heat capacity, etc.

3.6. Using the auxiliary component for fine tune regulation of the composition (nonstoichiometry) of inorganic solid bodies of variable composition

The AC method can be used not only for research purposes, but to solve problems relating to the regulation of the composition (nonstoichiometry) of inorganic compounds. For such cases, the discussed method is close to classical chemical (gas) transport reactions (CTRs). It is different from traditional CTRs in the fact that in this case the original sample is not exposed to oversublimation: due to the strict selectivity of the reaction of type (2), only a change in the ratio of components occurs in the sample.

The main idea of the method is that depending on conditions the selective chemical gas transport reaction can occur in the forward direction (extraction of the component from the sample) or in the reverse direction (saturation of the sample with a transported component [91-95]. The regulation of the content is carried out in a closed system (ampoule) where the sample and the batch are placed. The latter serves as a source or a getter of the transported component. The vapour in the ampoule consists of vapours of different forms of the transport component which provide for the selective transport. According to the findings in $[91,94,95]$, the direction of the selective chemical gas transport reaction (SSCTR) should only be regulated by the temperatures of the sample $\left(T_{1}\right)$ and the batch $\left(T_{2}\right)$ and the composition of the batch $\left(x_{1}\right)$. The evolution of the formulations of the sample and the batch is completed when the system reaches the steady state where there is no mass transfer. It can be said that the composition of the sample "adjusts" to the variables: $T_{2}, T_{1}$, and $x_{1}$. The following condition can be the empirical criterion to achieve the steady state:

$K_{P}^{\#}(1)=K_{P}^{\#}(2)$,

where

$K_{P}^{\#}(1)=f\left(T_{1}, x_{1}\right) ; K_{P}^{\#}(2)=f\left(T_{2}, x_{2}\right)([91,94])$.

Both for problems relating to the research of phase diagrams and equilibria and for the practical regulation of the composition the right choice of the auxiliary components is only possible if it meets a number of requirements $[86,87,91,94,95]$ :
1. Comparable amounts of $Z$ and $X z q_{q}$ molecular forms in the vapour in equilibrium (2).

2 . The absence of binary or ternary compounds between the transport component $Z$ and the second (non-transported) component $Y$ of the sample and the batch (the condition of the third component indifference in relation to the second component).

3. Almost complete insolubility of the $Z$ component in the studied or adjusted $X_{m} Y_{n}$ phase.

4. Preservation of the non-volatility of the condensed $X_{m} Y_{n}$ sample under the experimental conditions.

The SSCTR method can be especially useful when the material with the required structure is relatively easy to synthesise, however, it is difficult to precisely control its composition (e.g. due to low volatility). Thus, in [91-98], we demonstrated the possibility of fine tuning the nonstoichiometric composition and properties of gallium, indium, and copper selenides and sulphides.

It should be noted that it is not always possible to separate the "applied" and "research" possibilities of the auxiliary component method. For example, it was shown in $[93,95]$ that the selenium-enriched part of the homogeneity range of the gallium monoselenide (GaSe) has two phases: $\gamma$-modification of GaSe at high temperatures (> $1000 \mathrm{~K}$ ) and $\varepsilon-\mathrm{GaSe}$ at low temperatures. The composition of the phase within the homogeneity range was set by the SSCTR method. Apparently, constrained kinetics and the difficulties in regulating the GaSe composition by traditional methods did not allow detecting the enantiotropic transition $\varepsilon \mathrm{GaSe} \leftrightarrow \gamma \mathrm{GaSe}$ earlier. Therefore, the $T-x$ - chart of the Ga Se system should have two phases closely spaced by their composition and separated by a narrow heterogeneous region (which is supported by the independent thermal analysis data [99]).

The adjustment of the composition of intermediate phases conducted for the sake of studying the phase diagram was also carried out in the In - S system. This adjustment was performed using a modified (considering the specific nature of equilibria in the $\mathrm{In}-\mathrm{Cl}$ system) SSCTR method [96]. As a result, it was possible to show in $[88,90$, 96] that the $\operatorname{In}_{3-\mathrm{x}} \mathrm{S}_{4}$ cubic phase (with a structural type of defect reversed spinel) has a wide range of homogeneity (from $\sim 58.0$ to $59.9 \mathrm{~mol} \%$ of S) that 
changes little with temperature. As has already been noted above, the behaviour of the chemical potential of indium in the homogeneity range indicates a tendency to break the homogeneity range into individual phases. The attempts to obtain compositions with a greater content of sulphur at temperatures below $415^{\circ} \mathrm{C}$ led to a phase change with symmetry decreased to tetragonal and the formation of the $\alpha-\operatorname{In}_{2} S_{3}$ independent phase which almost exactly corresponded to the related stoichiometry. The data relating to the phase equilibria in the In - S system were verified by independent methods without using an AC [100].

In recent papers $[101,102]$, we were able to develop a method of chemical transport reactions to regulate the composition of the binary phases and to apply it to obtain single crystals of ferric sulphides with a controlled phase and nonstoichiometric composition. The novelty of the developed and applied technique was that a liquid phase based on iron dihalogenide melts was used as a carrier medium for the transported component (iron). Apart from the nature of the transport agent (melt) and the temperature, the composition of ferric sulphides was adjusted by the pressure of sulphur vapour. It should be noted that the substance transfer through the liquid phase in reactions similar in chemistry to gas transfer is very rare in experimental chemistry.

In our opinion, it is also promising to use the auxiliary component to create catalytic materials. It is known that highly disordered metals with high chemical and catalytic activity are often called skeleton metals (Ni, $\mathrm{Cu}, \mathrm{Ag}$, etc.). To produce them, first a metallide is normally synthesised which is formed by a $d$-metal remaining thereafter in the "skeleton" and by the second chemically active component (Al, Si, etc.). The latter is then removed by leaching. However, this method is unsuitable in some cases: primarily for reactions that must occur under anhydrous conditions.

$[103,104]$ considered a "dry" method to create activated metals based on the SSCTR method. The main idea of the method is to remove the active component from the metallide into the gas phase. For example:

$$
\begin{aligned}
& \mathrm{Al}^{\prime \prime}<\text { from the alloy }>+\mathrm{AlI}_{3}{ }^{\prime}=3 \mathrm{AlI}^{\prime} \\
& \text { or } \\
& \mathrm{Ga}^{\prime \prime}<\text { from the alloy }>+\mathrm{GaI}_{3}{ }^{\prime}=3 \mathrm{GaI}^{\prime} .
\end{aligned}
$$

Metallides in the $\mathrm{Cu}-\mathrm{Ge}, \mathrm{Ni}-\mathrm{Ga}, \mathrm{Cu}-\mathrm{Ga}$ systems were used to show the selective removal of the active component. Gallium or germanium were removed from alloys by means of transport reactions with the participation of germanium and gallium iodides and chlorides. To create a catalyst, the active component was removed in the obviously nonequilibrium conditions: in the vapour flow of the transport agent. Further, [104] compared the catalytic activities of nickel materials produced by a conventional method (Al leaching from the $\mathrm{NiGa}_{4}$ phase by the $\mathrm{KOH}$ solution) and substances produced by using the SSCTR method. Reactions of the reduction of nitrobenzene to aniline by means of hydrazine and conversion of benzyl alcohol vapours to toluene (benzene) and benzaldehyde were used as test reactions. For the latter conversion the content of decomposition products was studied depending on the process conditions (temperature, vapour flow rate) and the conditions of the catalyst's preparation. [104] also showed the possibility to increase the catalytic activity of nickel by introducing a transport agent directly into the reaction mixture that had been passed through a metallide. $\mathrm{NH}_{4} \mathrm{Cl}$ and $\mathrm{n}-\mathrm{C}_{4} \mathrm{H}_{9} \mathrm{Cl}$ were used as such activator agents. [105] showed the possibility of activating the surface of the nickel-containing material, which involved, on the contrary, a partial removal of nickel atoms from the nearsurface region by a selective reaction with the formation of nickel carbonyl:

$\mathrm{Ni}^{\prime \prime}<$ from the alloy $>+\mathrm{CO}^{\prime}=\left[\mathrm{Ni}(\mathrm{CO})_{4}\right]^{\prime}$

Most recently, the development of the auxiliary component method has been based on the spectrophotometric experimental resources. Scanning the vapour absorption spectra with the participation of the AC allows independently determining the concentrations (partial pressures) of various AC forms in the vapour (for example, $\mathrm{GaI}$ and $\mathrm{GaI}_{3}$ ) instead of the total vapour pressure in classical manometric methods. To calculate the $K_{P}^{\#}$ value, which is a key value for the measurements, the partial pressure data are necessary. An important feature of the newly developed experimental capabilities is an in-situ study of the spectra, i.e. the study of the vapour that is in contact with a condensed phase should be conducted 
directly under experimental conditions: at high temperatures (up to $900{ }^{\circ} \mathrm{C}$ ) and pressures other than the atmospheric pressure (up to $3 \cdot 10^{5} \mathrm{~Pa}$ ). The considered spectrophotometric method with the application of an AC was used to verify homogeneous and heterogeneous equilibria in the $\mathrm{Ga}$ - I [106], In - Cl [107] systems and to specify the phase diagram of the $\mathrm{Ga}-\mathrm{S}$ system in the high-temperature region $\left(>800^{\circ} \mathrm{C}\right)[108-110]$.

\section{Conclusion}

It should be noted that this review does not aim to cover all the areas in which the research has been conducted and the results have been achieved by that section of the scientific school of Ya A. Ugai which has been developing methods for the research and synthesis of semiconductor materials with expressed bulk properties. Beyond the scope of this paper are the results of the study of the $\mathrm{A}^{\mathrm{III}} \mathrm{B}^{\mathrm{V}}$ binary and ternary diamondlike phases, new methods of thermal analysis (chromatographic analysis) and manometric methods (laser null-manometry), and a number of other achievements. The main focus of this article, as can be seen from the text, is on:

- the investigation of $P-T-x$ diagrams of the $\mathrm{A}^{\mathrm{IV}}-\mathrm{B}^{\mathrm{V}}, \mathrm{A}^{\mathrm{IV}}-\mathrm{B}^{\mathrm{V}}-\mathrm{C}^{\mathrm{V}}$, and the $\mathrm{A}^{\mathrm{III}}-\mathrm{B}^{\mathrm{VI}}$ systems with emphasis on the study of the relationship between pressure $(P)$ and other thermodynamic variables $(T, x)$;

- the development of methods for the research and synthesis of intermediate phases with variable compositions (properties) in these systems.

Let us summarise the achievements in this area.

1. Using a set of complementary methods (the null-manometric method with two-way vacuuming of the membrane chamber, the differential thermal method with controlled vapour pressure, the extrapolation method with the introduction of an indifferent solvent, and standard methods of physico-chemical analysis), $P-T-x$ diagrams of the $\mathrm{A}^{\mathrm{IV}}-\mathrm{B}^{\mathrm{V}}$ systems were constructed; the positions of regions of intermediate phases were defined, and their types of melting and corresponding coordinates $(P, T, x)$ were determined. In particular, these methods in combination with structural studies were used to show that the monoarsenide (GeAs) and diarsenide $\left(\mathrm{GeAs}_{2}\right)$ in the $\mathrm{Ge}-\mathrm{As}$ system are independent intermediate phases with similar but different structures.

Semiconductor silicon and germanium phosphides and arsenides are characterised by a pronounced layered structure, the atoms within a layer are bound by strong covalent bonds, however, between the layers there are weak van der Waals forces. Favourable size factor affects the antistructure disordering in these phases, which has a decisive influence on the defect formation mechanism. Thus, the dominant defects are ionised antistructural defects of the $\mathrm{A}_{\mathrm{B}}^{\prime}$ and $\mathrm{B}_{\mathrm{A}}{ }_{\mathrm{A}}$ type. The study of micro- $P-T-x$ diagrams of the corresponding systems served as the foundation for the development of modes of obtaining crystals with reproducible properties.

In systems with the participation of tin ( $\mathrm{Sn}$ $\left.B^{v}\right)$ the phases with stoichiometry close to $\mathrm{Sn}_{4} \mathrm{~B}_{3}$ are stable. In addition, there are two more stable phases in the tin - phosphorus system, $\mathrm{Sn}_{3} \mathrm{P}_{4}$ and $\mathrm{SnP}_{3}$. A similar crystal structure with the $\mathrm{R} \overline{3} \mathrm{~m}$ space group similar to the structure of elements in the arsenic subgroup was revealed for all binary compounds. What is more, disparity of bonds is another characteristic feature of the structure. Such a layered crystalline structure allows for the intercalation of ions and molecules into the interlayer space.

The study of the temperature dependence of the saturated vapour pressure by means of opticaltensimetric methods in combination with the results of differential thermal analysis allowed constructing the $P-T-x$ diagram of the $S n-P$ system. The coordinates of four-phase equilibria points: of the synthetic $\left(\mathrm{SSn}_{4} \mathrm{P}_{3}+\mathrm{V}+\mathrm{L}_{1}+\mathrm{L}_{2}\right)$ and eutectic $\left(\mathrm{L}+\mathrm{V}+\mathrm{Sn}_{4} \mathrm{P}_{3}+\mathrm{SnP}_{3}\right)$ types were determined. It was shown that the $\mathrm{Sn}_{3} \mathrm{P}_{4}$ intermediate phase is only formed as a result of prolonged annealing of samples at a temperature below $673 \mathrm{~K}$. The annealing of the $\mathrm{Sn}_{3} \mathrm{P}_{4}$ sample obtained by the two-temperature method at a temperature of 753$773 \mathrm{~K}$ leads to its complete decomposition into the adjacent phases, $\mathrm{Sn}_{4} \mathrm{P}_{3}$ and $\mathrm{SnP}_{3}$. The detection of the $\mathrm{L} \leftrightarrow \mathrm{Sn}_{4} \mathrm{P}_{3}+\mathrm{SnP}_{3}$ eutectic equilibrium $(T \approx 824$ $\mathrm{K})$ in the $\mathrm{Sn}-\mathrm{P}$ binary system suggests a significant difference of the obtained $T-x$ diagram from the data available in the literature.

2. Compounds of the $\mathrm{A}^{\mathrm{IV}} \mathrm{B}^{\mathrm{V}}$ class are characterised by a similarity in the nearest atom coordination in compounds to their coordination 
in simple substances. Thus, the structural motif of the anion former has a great impact on the crystal-chemical structure of phases. As a consequence, solid solutions are quite easily formed in ternary systems based on $\mathrm{A}^{\mathrm{IV}} \mathrm{B}^{\mathrm{V}}$ compounds with anionic substitution, while in the case of cation substitution, even prolonged homogenising annealing does not result in a noticeable region of solid phase solubility. Solid solutions are formed quite easily in $\mathrm{Ge}-\mathrm{As}-\mathrm{P}$ and $\mathrm{Si}$ - As - PGe systems, however, due to the different crystal-chemical structures of silicon phosphide and arsenide, the latter system has a heterogeneous region corresponding to the joint presence of the component-based solid solutions.

The Sn-As-P ternary system has a continuous series of solid solutions between tin phosphide and arsenide with the composition of $\mathrm{Sn}_{4} \mathrm{~B}_{3}$ ( $\alpha$-solid solution). The $T-x$ diagram of the $\mathrm{Sn}_{4} \mathrm{P}_{3}-$ $\mathrm{Sn}_{4} \mathrm{As}_{3}$ polythermal cross section was constructed. The peritectic melting of tin arsenide and the decomposition of $\mathrm{Sn}_{4} \mathrm{P}_{3}$ by a synthetic schema resulted in three-phase regions in the diagram $\left(\mathrm{Sn}_{4} \mathrm{P}_{3}+\mathrm{SnAs}+\mathrm{L}\right)$ and $\left(\mathrm{Sn}_{4} \mathrm{P}_{3}+\mathrm{L}_{1}+\mathrm{L}_{2}\right)$. The examination of a number of polythermal cross sections of the $\mathrm{Sn}-\mathrm{As}-\mathrm{P}$ system showed the existence of extended regions of solid phase solubility based on tin monoarsenide $\beta$-solid solutions) and the $\mathrm{SnP}_{3}$ phase ( $\gamma$-solid solutions).

Available data on phase diagrams make it easy to outline methods for growing single crystals of intermediate phases of solid solutions with set compositions and, therefore, with set properties in the $\mathrm{A}^{\mathrm{IV}}-\mathrm{B}^{\mathrm{V}}$ and $\mathrm{A}^{\mathrm{IV}}-\mathrm{B}^{\mathrm{V}}-\mathrm{C}^{\mathrm{V}}$ systems.

3. Physico-chemical foundations for a new manometric method to determine $P T x$ diagrams of binary systems by using an auxiliary component (AC) were developed. The requirements for the $\mathrm{AC}$ and heterophase equilibria were formulated. The thermodynamic analysis of a number of systems established that the tensimetric study of equilibria with the participation of an AC can be used: $a$ ) to construct phase diagrams of binary systems; $b$ ) to scan homogeneity ranges; $c$ ) to calculate chemical potentials of the components; d) to determine integral thermodynamic properties. The validity of these conclusions was confirmed by experimental manometric research and the construction of phase diagrams of the $\mathrm{Ga}-\mathrm{Se}, \mathrm{Ga}-\mathrm{S}$, In $-\mathrm{S}$ binary systems.
$T-x$ and $p_{i}-T \mu_{\mathrm{Ga}}-T$-diagrams of these systems were determined. Integral thermodynamic characteristics of gallium monochalcogenides, $\mathrm{GaS}$ and $\mathrm{GaSe}$, were calculated.

4. New types of diagrams $\left(K_{P}^{\#}-\mathrm{T}, K_{P}^{\#}-\mathrm{T}-x\right)$ were proposed and determined for the $\mathrm{Ga}-\mathrm{Se}-\mathrm{I}$ and $\mathrm{Ga}-$ S-I systems which provide a basis for determining the conditions of the nonstoichiometry regulation by means of selective CTRs and are used to specify the boundaries of the homogeneity ranges of the binary phases. The homogeneity ranges of gallium monoselenide and monosulphide were determined. It was found that the data are consistent when different components $(\mathrm{Cl}, \mathrm{I})$ in different phase relations are used in the systems (the method of "the AC only in vapour" and "the method of gas solubility").

5. Tensimetric experiments without the participation of the AC were used to study phase diagrams and homogeneity ranges of the intermediate phases in the $\mathrm{Si}$ As and Ge As systems. Phase diagrams of silicon and germanium arsenides were compared with previously constructed diagrams of gallium and indium monochalcogenides based on the similarity of structures and the nature of chemical bonds in these groups of compounds. It was revealed that the following important peculiarity is common for the homogeneity ranges of these compounds: narrow over the entire range of temperatures homogeneity ranges of this compounds have sharp (up to a few percent) extensions in areas close to the maximum temperatures of phase melting. Such an extension in case of GaSe leads to the formation of a retrograde solidus in a narrow temperature range $(\sim 60 \mathrm{~K})$. For germanium diarsenides such expansion of the homogeneity range (up to $1.8 \mathrm{~mol} \%$ of As) occurs in an even smaller temperature range. A hypothesis was made according to which the peculiarities of homogeneity ranges of the considered layered phases similar in terms of structure are related to the formation of interlayer interstitial defects (i.e. autointercalation) at premelting temperatures.

6. A new method for nonstoichiometry regulation was developed and applied using nondestructive selective chemical transport reactions (i.e. with the participation of the AC). The method is based on the introduction or removal of one of the sample components by means of a selective 
chemical transport reaction conducted in the iso- or non-isothermal conditions. It was shown theoretically and experimentally that the direction of selective mass transfer, the introduction or removal of a component from the sample, is only determined by three parameters: temperatures $\left(T_{2}\right.$, $T_{1}$ ) which the sample and the batch are exposed to (a donor or a getter of the component chemically transferred through the gas), and the batch composition $\left(x_{1}\right)$. Transport stops when stationary states are achieved. What is more, the composition of the regulated sample $\left(x_{2}\right)$ is determined by the same three parameters $\left(T_{2}, T_{1}, x_{1}\right)$.

7. The method of selective chemical transport reactions was used to develop and apply a new method of directed synthesis of materials with the high reactivity based on the intermetallides of the GaNi system. It was shown that it is possible to increase the efficiency of the catalytic activity of such disturbed metals by introducing directly into the reaction process activator additives $\left(n-\mathrm{C}_{4} \mathrm{H}_{9} \mathrm{Cl}, \mathrm{NH}_{4} \mathrm{Cl}\right)$ which remove the residues of the activating component $(\mathrm{Ga})$ from the material.

8 . The new method of spectrophotometric studies based on the AC (hydrogen) equilibria quenching with indium sulphides was used to study the phase diagram of the InS system. It was proved that between the $\mathrm{In}_{3-\mathrm{x}} \mathrm{S}_{4}$ and $\mathrm{In}_{2} \mathrm{~S}_{3}^{\prime}$ phases (low-temperature modification) there is a narrow heterogeneous range which is limited from above by the temperature of the peritectic decomposition of the $\operatorname{In}_{2} \mathrm{~S}_{3}^{\prime}$ phase $\left(415^{\circ} \mathrm{C}\right)$. The $\operatorname{In}_{3-x} \mathrm{~S}_{4}$ homogeneity range extends from about $\sim 58.0$ mol\% of S to $\sim 59.9$ mol\% and is not particularly dependent on temperature (at $T \leqslant 725^{\circ} \mathrm{C}$ ). A tendency to the decomposition of solid solutions based on the $\operatorname{In}_{3 x} \mathrm{~S}_{4}$ phase with extended homogeneity with a spinel structure was shown. Temperature dependences of sulphur vapour pressure $\left(\mathrm{S}_{2}\right)$ were determined in the equilibria of different nature with the participation of condensed indium sulphides. It was established that there is a good correlation between the results of spectrophotometric studies within the developed methodology and the mass spectrometric data.

9. As a result of applying the new in situ spectrophotometric method which involved using gallium iodides as an AC, and as a result of hightemperature X-ray studies, it was established that at temperatures below $825{ }^{\circ} \mathrm{C}$ the $\mathrm{Ga}-\mathrm{S}$ system does not have intermediate solid phases but $\mathrm{GaS}$ and $\mathrm{Ga}_{2} \mathrm{~S}_{3}$. In contrast, the high-temperature portion of the diagram of the $\mathrm{Ga}-\mathrm{S}$ system is complex and comprises of two more phases with stoichiometries from 59 to $60 \mathrm{~mol} \%$.

We would like to conclude the review by mentioning the contributions of a number of employees involved in this collective work. An enormous contribution was made by the closest colleague of Ya. A. Ugai, Evgeny G. Goncharov. It is difficult to overestimate the importance of the contribution of the prematurely deceased A. E. Popov, whose works largely determined the achievements of the employees that surrounded him in the late 1980s - early 1990s. We would like to mention the works by the employees of the Faculty of Chemistry of Voronezh State University, T. P. Sushkova, A. V. Kosyakov, A. V. Naumov, E. Yu. Proskurina, and D. N. Turchen. Without the contributions of these professionals it would have been impossible to get the results presented herein. However, it has to be mentioned that all of these specialists worked in the direction laid by the founder of the scientific school, Ya. A. Ugai.

\section{Author contributions}

All authors made an equivalent contribution to the preparation of the publication

\section{Conflict of interests}

The authors declare that they have no known competing financial interests or personal relationships that could have influenced the work reported in this paper.

\section{References}

1. http://www.science.vsu.ru/resources/schools/ ugai.pdf

2. Olesinski R. W., Abbaschian G. J. Bulletin of Alloy Phase Diagrams. 1985;6(3): 250-254. https://doi. org/10.1007/bf02880409

3. Massalski T. B. Binary alloy phase diagrams. ASM International: 1986; p. 187.

4. Miller L., Kannewurf C.R. Optical properties of single crystal silicon arsenides. Journal of Physics and Chemistry of Solids. 1970;31(4): 849-855. https://doi. org/10.1016/0022-3697(70)90218-0

5. Rau J. W., Kannewurf C. R. Optical absorption, reflectivity and electrical conductivity in GeAs. Physical Review B. 1977;3(8): 2581-2587.https://doi.org/10.1103/ physrevb.3.2581

6. Ugai Ya. A., Gladyshev N. F., Goncharov E. G. Tenzimetricheskoe issledovanie sistemy Ge-As [Tensimetric study of the Ge-As system]. Russian Journal of Inorganic 
Chemistry. 1978;23(4): 1065-1068. Available at: https:// www.elibrary.ru/item.asp?id=29096579 (In Russ.)

7. Goncharov E. G., Gladyshev N. F., Ugai Ya. A. Fiziko-khimicheskaya priroda promezhutochnykh faz v sisteme germanii - mysh'yak [Physicochemical nature of intermediate phases in the germanium - arsenic system]. Russian Journal of Inorganic Chemistry. 1977;22(7): 1951-1956. Available at: https://www.elibrary.ru/item.asp?id=29091830 (In Russ.)

8. Ugai Ya. A., Miroshnichenko S. N., Goncharov E. G. Issledovanie $R-T-x$ diagrammy sistemy Si-As [Study of the $P-T-x$ diagram of the Si-As system]. Izvestiya AN SSSR. Neorganicheskie materialy (Inorganic Materials). 1974;10(10): 174-1777. Available at: https://www.elibrary.ru/item.asp?id=29085699 (In Russ.)

9. Popov A. E., Zavrazhnov A. Yu., Averbakh E. M., Goncharov E. G. P-T-x diagramma diarsenida kremniya [P-T-x diagram of silicon diarsenide]. Inorganic Materials. 1993;29(11): 1458-1461. Available at: https://www.elibrary.ru/item.asp?id=29109931 (In Russ.)

10.Ugai Ya.A., Sokolov L. I., Goncharov E. G., Makarov V. S. R-T-x diagramma sostoyaniya i termodinamika fazovykh ravnovesii v sisteme kremnii - fosfor [P-T-X state diagram and thermodynamics of phase equilibria in the silicon - phosphorus system]. Inorganic Materials. 1987;32(5): 1198-1200. Available at: https://www.elibrary.ru/item.asp?id=29121653 (In Russ.)

11. Ugai Y. A., Semenova G. V., Sokolov L. I., Goncharov E. G. Thermal dissociation of silicon monophosphide. Russian Journal of Inorganic Chemistry. 1987;32(6): 875-877.

12. Ugai Ya. A., Sokolov L. I., Goncharov E. G. Termograficheskoe issledovanie razreza sistemy $\mathrm{Ge}-\mathrm{P}-\mathrm{Pb}$ [Thermographic study of the Ge-P-Pb system section]. Izvestiya AN SSSR. Neorganicheskie materialy (Inorganic Materials). 1973;9(8): 1445-1447. Available at: https:// www.elibrary.ru/item.asp?id=29085659 (In Russ.)

13. Goncharov E. G., Sokolov L. I., Ugai Ya. A. Diagramma sostoyaniya i nekotorye termodinamicheskie parametry sistemy Ge-P [P-T-x diagram of the state of the Ge-P system]. Russian Journal of Inorganic Chemistry. 1975;20(9): 2452-2454. Available at: https://www. elibrary.ru/item.asp?id=29085724 (In Russ.)

14. Ugai Ya. A., Sokolov L. I., Goncharov E. G., Pshestanchik V. R. P-T-x diagramma sostoyaniya sistemy Ge-P i termodinamika vzaimodeistviya komponentov [P-T-x diagram of the state of the Ge-P system and the thermodynamics of the interaction of the components]. Russian Journal of Inorganic Chemistry. 1978;23(7): 1907-1911. Available at: https://www.elibrary.ru/item. asp?id=29096578 (In Russ.)

15. Ugai Ya. A., Popov A. E., Goncharov E. G. Oblast' gomogennosti arsenida germaniya [Homogeneity region of germanium arsenide]. Russian Journal of Inorganic Chemistry. 1982;27(7): 1782-1787. Available at: https:// www.elibrary.ru/item.asp?id=29096104 (In Russ.)

16. Zavrazhnov A. Yu., Turchen D. N., Goncharov E. G., Fedorova M. V. P-T-X phase diagram of the
Ge-As system near germanium diarsenide. Inorganic Materials. 1998;34(7): 637-641.

17. Ugai Ya. A., Popov A. E., Goncharov E. G., Lukin A. N., Samoilov A. M. Elektrofizicheskie svoistva i oblast' gomogennosti arsenida germaniya [Electrophysical properties and homogeneity region of germanium arsenide]. Izvestiya AN SSSR. Neorganicheskie materialy (Inorganic Materials). 1983;19(2): 190-192. Available at: https://www.elibrary.ru/item.asp?id=29095704 (In Russ.)

18. Goncharov E. G., Popov A. E., Zavrazhnov A. Yu. Poluprovodnikovye fosfidy i arsenidy kremniya i germaniya [Semiconductor phosphides and arsenides of silicon and germanium]. Inorganic Materials. 1995;31(5): 579-591. Available at: https://www.elibrary.ru/item. asp?id=29113633 (In Russ.)

19. Lukin A. N. Elektricheskie svoistva monoklinnykh kristallov gruppy $\mathrm{A}^{\mathrm{IV}} \mathrm{B}^{\mathrm{V}}$. Fiziko-khimicheskie protsessy v poluprovodnikakh i na ikh poverkhnosti [Electrical properties of monoclinic crystals of the AIVBV group. In: Physicochemical processes in semiconductors and on their surfaces / Collection of articles]. Voronezh: VSU Publ.; 1981. p. 148-151. (In Russ.)

20. Lukin A. N., Sokolov L. I., Kavetskii V. S. Elektrofizicheskie i opticheskie svoistva fosfida germaniya. Khimiya i tekhnologiya fosfidov i fosforosoderzhashchikh splavov [Electrophysical and optical properties of germanium phosphide. In: Chemistry and technology of phosphides and phosphorus-containing alloys / Collection of articles] Kiev: 1979. p. 133-135. (In Russ.)

21. Schmetterer C. Interaction of Sn-based sSolders with $\mathrm{Ni}(\mathrm{P})-\mathrm{Substrates}$ : The Ni-P, P-Sn and $\mathrm{Ni}-\mathrm{P}-\mathrm{Sn}$ phase diagrams: Diss. Dr. rer. Nat. Wien: 2009. 143 p.

22. Schmetterer C., Ganesan R. Ipser H. Interaction of Sn-based solders with $\mathrm{Ni}(\mathrm{P})$ substrates: phase equilibria and thermochemistry. In: Lead-Free Solders: Materials Reliability for Electronics. 2012. p. 71-118. https://doi.org/10.1002/9781119966203.ch4

23. Shevelkov A. V. Thermoelectric materials: an introduction. Dalton Trans. 2010;39(4): 977-977. https://doi.org/10.1039/b924863n

24. Hashimoto K., Kato Z., Kumagai N., Kamio K., Hirose K. Sn - P alloys for rapid and stable production of tin solution for tin plating. ECS Transactions. 2006;1(4): 525-532. https://doi.org/10.1149/1.2215536

25. Kim Y., Hwang H., Yoon C. S., Kim M. G., Cho J. Reversible lithium intercalation in teardrop-shaped ultrafine $\mathrm{SnP}_{0.94}$ particles: anode material for lithium-ion batteries. Advanced Materials. 2007;19(1): 9296. https://doi.org/10.1002/adma.200600644

26. Kim Y., Kim Y., Choi A., Woo S., Mok D., Choi N.-S., ... Lee K. T. Tin phosphide as a promising anode material for Na-ion Batteries. Advanced Materials. 2014;26(24): 4139-4145. https://doi.org/10.1002/ adma. 201305638

27. Liu S., Zhang H., Xu L., Ma L. Synthesis of hollow spherical tin phosphides $\left(\mathrm{Sn}_{4} \mathrm{P}_{3}\right)$ and their high adsorp- 
tive and electrochemical performance. Journal of Crystal Growt. 2016;438: 31-37. https://doi.org/10.1016/j. jcrysgro.2015.12.018

28. Liu S., Zhang H., Xu L., Ma L. Solvothermal preparation of tin phosphide as a long-life anode for advanced lithium and sodium ion batteries. Journal of Power Sources. 2016;304: 346-353. https://doi. org/10.1016/j.jpowsour.2015.11.056

29. Ueda A., Nagao M., Inoue A., et al. Electrochemical performance of all-solid-state lithium batteries with $\mathrm{Sn}_{4} \mathrm{P}_{3}$ negative electrode. Journal of Power Sources. 2013;244: 597-600. https://doi.org/10.1016/j.jpowsour.2013.01.061

30. Liu S., Li S., Li M., Yan L., Li H. Synthesis of tin phosphides $\left(\mathrm{Sn}_{4} \mathrm{P}_{3}\right)$ and their high photocatalytic activities. New Journal of Chemistry. 2013;37(3): 827-833. https://doi.org/10.1039/C2NJ41068K

31. Usui H., Sakata T., Shimizu M., Sakaguchi H. Electrochemical Na-insertion/extraction properties of Sn-P anodes. Electrochemistry. 2015;83(10): 810-812. https://doi.org/10.5796/electrochemistry.83.810

32. Doh C. VASP calculation on lithium reaction to tin phosphides. In: ECS Meeting Abstracts. 2014. 255 p. https://doi.org/10.1149/ma2014-01/2/255

33. Vivian A. C. The tin-phosphorus system. Journal of the Institute of Metals. 1920;23: 325-336.

34. Sushkova T. P., Kononova E. Yu., Savinova Yu. A., Dorokhina E. S., Semenova G. V. Intermediate phases in Sn - P system. Kondensirovannye sredy i mezhfaznye granitsy = Condensed Matter and Interphases. 2014;16(1): 210-214. Available at: https://www.elibrary.ru/item. asp?id=21785802 (In Russ., abstract in Eng.)

35. Proskurina E. Yu., Semenova G. V., Zavrazhnov A. Yu., Kosyakov A. V. P-T-x diagram of Sn - P system. Condensed media and interphase boundaries. 2015;17(4): 498-509. Available at: https://www.elibrary.ru/item.asp?id=25946590 (In Russ., abstract in Eng.)

36. Sushkova T. P., Proskurina E. Yu., Semenova G. V., Zavrazhnov A. Yu. Thermal stability of tin monophosphide. In: Science and Education: materials of the $X I$ international research and practice conference. Apr. $6^{\text {th }}-7^{\text {th }}, 2016$. Munich (Germany): 2016;1: 40-45.

37. Semenova G. V., Proskurina E. Yu., Sushkova T. P. T-x diagram of the $\mathrm{Sn}$ - P system. In: XX Mendeleev Congress on General and Applied Chemistry. Fundamental problems of chemical science. Abstracts. vol. 1. September 26-30, 2016. Yekaterinburg: 2016. p. 480. (In Russ.)

38. Zavrazhnov A. Yu., Semenova G. V., Proskurina E. Yu., Sushkova T. P. Phase diagram of the Sn - P system. In: 4th Central and Eastern European Conference on Thermal Analysis and Calorimetry (CEEC-TAC4). Abstracts. 28 - 31 August, 2017. Kishinev: 2017. p. 346.

39. Zavrazhnov A. Yu., Semenova G. V., Proskurina E. Yu., Sushkova T. P. Phase diagram of the Sn - P system. Journal of Thermal Analysis and Calorimetry. 2018;134(1): 475-481. https://doi.org/10.1007/s10973018-7123-0
40. Shevelyuhina A. V., Semenova G. V., Sushkova T. P. Phase diagram of the $\mathrm{Sn}-\mathrm{P}$ system at concentration of phosphorus over 70 mol\%. In: XVI International Conference on Thermal Analysis and Calorimetry (RTAC). Abstracts. 6 July 2020, Moscow (Russia). Moscow: 2020. p. 194.

41. Guo J., Liu Y., Ma Y., Zhu E., Lee S., Lu Z., ... Duan X. Few-layer GeAs field-effect transistors and infrared. Advanced Materials. 2018;30(21): 1705934. https://doi.org/10.1002/adma.201705934

42. Lee K., Synnestvedt S., Bellard M., Kovnir K. GeP and $\left(\mathrm{Ge}_{1-\mathrm{x}} \mathrm{Sn}_{\mathrm{x}}\right)\left(\mathrm{P}_{1-\mathrm{y}} \mathrm{Ge}_{\mathrm{y}}\right)(\mathrm{x} \approx 0.12, \mathrm{y} \approx 0.05)$ : Synthesis, structure, and properties of two-dimensional layered tetrel phosphides. ChemInform. 2015;46(18): 62-70. https://doi.org/10.1002/chin.201518016

43. Lee K., Kamali S., Ericsson T., Bellard M., Kovnir K. GeAs: Highly anisotropic van der Waals thermoelectric material. Chemistry of Materials. 2016;28(8): 2776-2785. https://doi.org/10.1021/acs.chemmater.6b00567

44. Pomerantseva E., Resini C., Kovnir K., Kolen`ko Yu. Emerging nanostructured electrode materials for water electrolysis and rechargeable beyond Li-ion batteries. Advances in Physics: X. 2017;2 (2): 211-253. https://doi.org/10.1080/23746149.2016.1273796

45. Zhao T., Sun Y., Shuai Z., Wang D. GeAs 2 : A IV-V group two-dimensional semiconductor with ultralow thermal conductivity and high thermoelectric efficiency. Chemistry of Materials. 2017;29(15): 6261-6268. https://doi.org/10.1021/acs.chemmater.7b01343

46. Proskurina E. Yu., Semenova G. V., Sushkova T. P. Phase equilibria in the Ge-As-Bi system. Proceedings of Voronezh State University. Series: Chemistry. Biology. Pharmacy. 2018;4: 27-34. Available at: https://www.elibrary. ru/item.asp?id=36664319 (In Russ., abstract in Eng.)

47. Semenova G. V., Kononova E. Yu., Sushkova T. P. Polythermal section Ge-SnAs of the Sn-As-Ge system. Russian Journal of Inorganic Chemistry. 2014;59(12): 1517-1521.https://doi.org/10.1134/s0036023614120225

48. Semenova G. V., Sushkova T. P., Proskurina E. Yu. Polythermal section Sn - GeAs of the Sn - As - Ge system. Proceedings of Voronezh State University. Series: Chemistry. Biology. Pharmacy. 2015;1: 49-53. Available at: https://www.elibrary.ru/item.asp?id=23478462 (In Russ., abstract in Eng.)

49. Proskurina E. Yu., Semenova G. V., Sushkova T.P. Topological scheme of phase equilibria in the Sn - As Ge system. Kondensirovannye sredy i mezhfaznye granitsy = Condensed Matter and Interphases. 2016;18(2): 241-247. Available at: https://www.elibrary.ru/item. asp?id=26023376 (In Russ., abstract in Eng.)

50. Proskurina E. Yu., Makagonov V. A, Semenova G. V., Sushkova T. P. Alloying with tin of the germanium monoarsenide. Proceedings of Voronezh State University. Series: Chemistry. Biology. Pharmacy. 2018;2: 41-47. Available at: https://www.elibrary.ru/item.asp?id=35350430 (In Russ., abstract in Eng.)

51. Semenova G., Proskurina E., Sushkova T., Semenov V. Phase diagram of the $\mathrm{Sn}-\mathrm{As}-\mathrm{Ge}$ system. Acta 
Chimica Slovenica. 2018;65(3): 662-669. https://doi. org/10.17344/acsi.2018.4333

52. Semenova G. V., Zabakhidze G. E., Goncharov E. G. Polythermal section SiAs-GeAs. Russian Journal of Inorganic Chemistry. 1997;42(10): 1596-1597.

53. Semenova G. V., Zabakhidze G. E., Goncharov E. G. Analysis of phase equilibria in the Si-Ge-As system. Russian Journal of Inorganic Chemistry. 1998;43(9): 1435-1437.

54. Ugai Ya. A., Muravyova S. N., Goncharov E. G. Diagramma sostoyaniya sistemy GeAs-GeP [State diagram of the GeAs-GeP system]. Izvestiya AN SSSR. Neorganicheskie materialy (Inorganic Materials). 1972;8(9): 1665-1666. (In Russ.)

55. Meshchaninova L. N., Goncharov E. G., Ugai Ya. A. R-T-x diagramma sostoyaniya sistemy SiAsSiP [P-T-X state diagram of the SiAs-SiP system]. Russian Journal of Inorganic Chemistry. 1980;25(11): 3084-3088. Available at: https://www.elibrary.ru/item. asp?id=29096734 (In Russ.)

56. Ugai Ya. A., Goncharov E. G., Semenova G. V., Lazarev V. B. Fazovye ravnovesiya mezhdu fosforom, mysh'yakom, sur'moi $i$ vismutom [Phase equilibria between phosphorus, arsenic, antimony and bismuth]. Moscow: Nauka Publ.; 1989. 233 p. (In Russ.)

57. Ugai Ya. A., Semenova G. V., Goncharov E. G. P-T-x diagramma sostoyaniya sistemy sur'ma mysh'yak [P-T-x diagram of the state of the antimony arsenic system]. Russian Journal of Inorganic Chemistry. 1985;30(6): 1532-1535. Available at: https://www.elibrary.ru/item.asp?id=28991560 (In Russ.)

58. Ugai Ya. A., Semenova G. V., Samoilov A. M., Goncharov E. G. Analiz fazovykh ravnovesii v sisteme $\mathrm{Sb}$ - As [Analysis of phase equilibria in the Sb-As system]. Izvestiya AN SSSR. Neorganicheskie materialy (Inorganic Materials). 1987;23(9): 1434-1437. Available at: https://www.elibrary.ru/item.asp?id=29030335 (In Russ.)

59. Ugai Ya. A., Semenova G. V., Goncharov E. G., Berendt $\mathrm{E}$. Issledovanie P-T-x diagrammy sistemy fosfor mysh'yak ekstrapolyatsionnym metodom [Study of the P-T-X diagram of the phosphorus - arsenic system by the extrapolation method]. Russian Journal of Inorganic Chemistry. 1979;24(12): 3344-3346. Available at: https:// www.elibrary.ru/item.asp?id=28999582 (In Russ.)

60. Ugai Ya. A., Semenova G. V., Goncharov E. G. Raschet sostava para v sisteme fosfor - mysh'yak [Calculation of the composition of steam in the phosphorus - arsenic system]. Russian Journal of Physical Chemistry A. 1979;53(4): 1019-1020. Available at: https:// www.elibrary.ru/item.asp?id=28998458 (In Russ.)

61. Ugai Ya. A., Semenova G. V., Goncharov E. G. Termodinamicheskii analiz fazovykh ravnovesii $\mathrm{V}$ sisteme fosfor - mysh'yak [Thermodynamic analysis of phase equilibria in the phosphorus - arsenic system]. Russian Journal of Physical Chemistry A. 1986;60(12): 2952-2954. Available at: https://www.elibrary.ru/item. asp?id=29003620 (In Russ.)
62. Krebs H., Weitz H., Worms K. H. Uber die strukture und eigenschaften der halbmetalls. Zeitschrift for anorganische und allgemeine Chemie. 1955;280(1/3): 119-133. https://doi.org/10.1002/zaac.19552800110

63. Krebs H., Holz W., Worms K. H. Eine neue rhombische arsen modifikation und ihre mischkristallbildunf mit schwarzen phosphor. Chemische Berichte. 1957;90(6): 1031-1037. https://doi.org/10.1002/cber.19570900624

64. Pang J., Bachmatiuk A., Yin Y., Trzebicka B. Applications of phosphorene and black phosphorus in energy conversion and storage devices. Advanced Energy Materials. 2018;8(8): 1702093. https://doi. org/10.1002/aenm.201702093

65. Zeng J., Cui P., Zhang Z. Half layer by half layer growth of a blue phosphorene monolayer on a $\mathrm{GaN}(001)$ substrate. Physical Review Letters. 2017;118(4): 46101. https://doi.org/10.1103/PhysRevLett.118.046101

66. Niu T. New properties with old materials: Layered black phosphorous. Nano Today. 2017;12: 7-9. https://doi.org/10.1016/j.nantod.2016.08.013

67.Zhu Z., Tománek D. Semiconducting layered blue phosphorus: A computational study. Physical Review Letters. 2014;112(17): 176802.https://doi.org/10.1103/ PhysRevLett.112.176802

68. Osters O., Nilges T., Bachhuber F., Pielnhofer F, Weihrich R., Schöneich M., Schmidt P. Synthesis and identification of metastable compounds: Black arsenic science or fiction? Angewandte Chemie International Edition. 2012;51(12): 2994-2997. https://doi. org/10.1002/anie.201106479

69. Goncharov E. G., Semenova G. V., Kalyuzhnaya M. I. Termograficheskoe issledovanie fazovoi diagrammy sistemy Ge-As-P [Thermographic study of the phase diagram of the Ge-As-P system]. Russian Journal of Inorganic Chemistry. 1992;37(8): 1895-1897. Available at: https://www.elibrary.ru/item.asp?id=29031293 (In Russ.)

70. Semenova G. V., Morozova A. A., Goncharov E. G., Dolgopolova E. A. Ge-As-P system. Russian Journal of Inorganic Chemistry. 1997;42(2): 266-268.

71. Semenova G. V., Morozova A.A., Goncharov E. G. Termodinamicheskii analiz R-T-kh- $\mathrm{u}$ fazovoi diagrammy sistemy Ge-As-P [Thermodynamic analysis of the $\mathrm{P}-\mathrm{T}-\mathrm{X}-\mathrm{y}$ phase diagram of the Ge-As-P system]. Russian Journal of Inorganic Chemistry. 1993;38(12): 2023-2025. Available at: https://www.elibrary.ru/item.asp?id=29029850 (In Russ.)

72. Goncharov E. G., Semenova G. V. Kalyuzhnaya M. I., Solov'ev N. E. Politermicheskii razrez SiAs - SiP [Polythermal section SiAs - SiP]. Russian Journal of Inorganic Chemistry. 1993;38(4): 709-710. Available at: https:// www.elibrary.ru/item.asp?id=29029856 (In Russ.)

73. Semenova G. V., Sushkova T. P., Dolgopolova E. A., Morozova A. A. Tverdye rastvory v sisteme SiAs - SiP [Solid solutions in the SiAs - SiP system]. Russian Journal of Inorganic Chemistry. 2003;48(4): 582-584. Available at: https://www.elibrary.ru/item. asp?id=17278755 (In Russ.) 
74. Semenova G. V., Morozova A. A., Goncharov E. G. Analiz fazovykh ravnovesii v sisteme Si-As-P [Analysis of phase equilibria in the Si-As-P system]. Russian Journal of Inorganic Chemistry. 1995;40(4): 658-660. Available at: https://www.elibrary.ru/item.asp?id=29053410 (In Russ.)

75. Semenova G. V., Goncharov E. G. Tverdye rastvory s uchastiem elementov pyatoi gruppy [Solid solutions with the participation of elements of the fifth group]. Moscow: Izd. MFTI Publ.; 2000. 160 p. (In Russ.)

76. Semenova G. V., Kononova E. Yu., Sushkova T. P. Polythermal section $\mathrm{Sn}_{4} \mathrm{P}_{3}-\mathrm{Sn}_{4} \mathrm{As}_{3}$ Russian Journal of Inorganic Chemistry. 2013;58(9): 1112-1114. https:// doi.org/10.1134/S0036023613090192

77. Kononova E. Yu. , Sinyova S. I., Semenova G. V., Sushkova T. P. Phase equilibria in the Sn-As-Ge and Sn-A-P systems. Journal of Thermal Analysis and Calorimetry. 2014;117(3):1171-1177. https://doi. org/10.1007/s10973-014-3883-3

78. Semenova G. V., Sushkova T. P., Zinchenko E. N., Yakunin S. V. Solubility of phosphorus in tin monoarsenide. Kondensirovannye sredy i mezhfaznye granitsy = Condensed Matter and Interphases. 2018;20(4): 644-649. https://doi.org/10.17308/kcmf.2018.20/639 (In Russ., abstract in Eng.)

79. Semenova G. V., Sushkova T. P., Tarasova L. A., Proskurina E. Yu. Phase equilibria in a $\mathrm{Sn}-\mathrm{As}-\mathrm{P}$ system with a tin concentrations less than 50 mol\%. Kondensirovannye sredy i mezhfaznye granitsy = Condensed Matter and Interphases. 2017;19(3): 408-416. https://doi.org/10. 17308/kcmf.2017.19/218 (In Russ., abstract in Eng.)

80. Sushkova T. P., Sheveljuhina A. V., Semenova G. V., Proskurina E. Yu. The SnAs-P polythermic section of Sn-As-P ternary system. Kondensirovannye sredy $i$ mezhfaznye granitsy = Condensed Matter and Interphases. 2019;21(2): 287-295. https: //doi.org/ 10.17308 /kcmf.2019.21/766

81. Liu C.-W., Dai J.-J., Wu S.-K., Diep N.-Q., Huynh S.-H., Mai T.-T., ... Luc H.-H.. Substrate-induced strain in 2D layered GaSe materials grown by molecular beam epitaxy. Scientific Reports. 2020;10(1): 12972. https://doi.org/10.1038/s41598-020-69946-4

82. Zhou X., Cheng J., Zhou Y., Cao T., Hong H., Liao Z., ... Yu D. Strong second-harmonic generation in atomic layered GaSe. Journal of the American Chemical Society. 2015;137(25): 7994-7997. https://doi. org/10.1021/jacs.5b04305

83. Olmstead M. A., Ohuchi F. S., Group III selenides: Controlling dimensionality, structure, and properties through defects and heteroepitaxial growth. Journal of Vacuum Science \& Technology A. 2021;39(2): 020801. https://doi.org/10.1116/6.0000598

84. Marvan P., Mazánek V., Sofer Z. Shear-force exfoliation of indium and gallium chalcogenides for selective gas sensing applications. Nanoscale. 2019;11(10): 4310-4317 https://doi.org/10.1039/C8NR09294J

85. Woods-Robinson R., Han Y., Zhang H., Ablekim T., Khan I., Persson K. A., Zakutayev A. Wide band gap chal- cogenide semiconductors. Chemical Reviews. 2020;120(9): 4007-4055.https://doi.org/10.1021/acs.chemrev.9b00600

86. Zavrazhnov A. Yu, Turchen D. N, Goncharov Eu. G., Zlomanov V. P. Manometric method for the study of P-T-X diagrams. Journal of Phase Equilibria. $2001 ; 22(4)$ : 482-490. https://d oi . org/10.1361/105497101770333063

87. Zavrazhnov A. Yu. Design of P-T-x diagrams for gallium chalcogenides with the use of an ancillary component. Russian Journal of Inorganic Chemistry. 2003;48(10): 1577-1590.

88. Kosyakov A. V., Zavrazhnov A. Yu., Naumov A. V., Sergeeva A. S. Specification of the phase diagram of system In-S according to spectrophotometric researches of balance between sulfide of indium and hydrogen. Proceedings of Voronezh State University. Series: Chemistry. Biology. Pharmacy. 2009;2: 28-39. Available at: https://www.elibrary.ru/item.asp?id=12992199 (In Russ., abstract in Eng.)

89. Kosyakov A. V., Zavrazhnov A. Y. Naumov A. V . Refinement of the In-S phase diagram using spectrophotometric characterization of equilibria between hydrogen and indium sulfides. Inorganic Materials. 2010;46(4): 343-345 (2010). https://doi.org/10.1134/ S0020168510040035

90. Zavrazhnov A. Y., Kosyakov A. V., Naumov A. V., Sergeeva A. V., Berezin S. S. Study of the In-S phase diagram using spectrophotometric characterization of equilibria between hydrogen and indium sulfides. Thermochimica Acta Journal. 2013;566: 169-174. https://doi. org/10.1016/j.tca.2013.05.031

91. Zavrazhnov A. Y., Turchen D. N., Naumov A. V., Zlomanov V. P. Chemical transport reactions as a new variant of the phase composition control. Journal of Phase Equilibria. 2003;24(4): 330-339. https://doi. org/10.1361/105497103770330316

92. Zavrazhnov A. Y., Turchen D. N., Naumov A. V., Zlomanov V. P. Chemical vapor transport as a means of controlling the composition of condensed phases. Inorganic Materials. 2004;40(2): 101-127. https://doi. org/10.1007/s10789-005-0056-6

93. Sidei V. I., Naumov A. V, Turchen D. N., Chukichev V.M. Upravlenie sostavom monoselenida galliya v predelakh oblasti gomogennosti i diagnostika nestekhiometrii GaSe [Controlling the composition of gallium monoselenide within the homogeneity region and diagnostics of GaSe nonstoichiometry]. Kondensirovannye sredy $i$ mezhfaznye granitsy = Condensed Matter and Interphases. 2004;6(4): 322-325. Available at: https:// www.elibrary.ru/item.asp?id=29833369 (In Russ.)

94. Zavrazhnov A. Yu., Zartsyn I. D., Naumov A. V., Zlomanov V. P., Davydov A. V. Composition control of low-volatile solids through chemical vapor transport reactions. I. Theory of selective chemical vapor transport. Journal of Phase Equilibria and Diffusion. 2007;28(6): 510-516. https://doi.org/10.1007/s11669-007-9200-0

95. Zavrazhnov A., Naumov A., Sidey V., Pervov V. Composition control of low-volatile solids through 
chemical vapor transport reactions. III. The example of gallium monoselenide: Control of the polytypic structure, non-stoichiometry and properties. Thermochimica Acta Journal. 2012;527: 118124. https://doi. org/10.1016/j.tca.2011.10.012

96. Zavrazhnov A. Yu., Naumov A., Riazhskikh M., Pervov V. Chemical vapor transport for the control of composition of low-volatile solids: II. The composition control of indium sulfides: Technique of the charge dilution. Thermochimica Acta Journal. 2012;532: 96102. https://doi.org/10.1016/j.tca.2010.10.004

97. Zavrazhnov A. Y., Naumov A. V., Sergeeva A. V., Sidey V. I. Selective chemical vapor transport as a means of varying the composition of nonstoichiometric indium sulfides. Inorg Mater 2007;43(11): 1167-1178. https://doi.org/10.1134/S0020168507110039

98. Zavrazhnov A. Yu., Naumov A., Sergeeva A., Semenov V., Pervov V. Novel approach to the design of optoelectronic heterostructures based on copper and indium sulfides. J. Fudan University (Fudan Xuebao, China). 2007;46(5): 730.

99. Kosyakov A. V., Nekrylov I. N., Brezhnev N. Yu., Berezin S. S., Malygina E. N., Zavrazhnov A. Yu. Tx diagram of the $\mathrm{Ga}$ - Se system in the composition range from 48.0 to $61.5 \%$ Se according to thermal analysis data. Kondensirovannye sredy $i$ mezhfaznye granitsy = Condensed Matter and Interphases. 2019;21(4): 519-527. https://doi.org/10.17308/kcmf.2019.21/2363 (In Russ., abstract in Eng.)

100. Berezin S. S., Berezina M. V., Zavrazhnov A. Y., Kosyakov A. V., Sergeeva A. V., Sidei V. I. Phase transformations of indium mono- and sesquisulfides studied by a novel static thermal analysis technique. Inorganic Materials. 2013;49: 555-563. https://doi.org/10.1134/ S0020168513060010

101. Berezin S. S., Spesivtseva A. P., Zavrazhnov A. Yu., Okushko A. I. Iron sulfides crystal growth at controlled sulfur pressure with the use of metal-halogenide melts. 2015;17(4):412-416. Available at: https:// www.elibrary.ru/item.asp?id=25946576 (In Russ., abstract in Eng.)

102. Zavrazhnov A. Y., Naumov A., Kosyakov A., Berezin S., Volkov V., Sergeeva A. The iron sulfides crystal growth from the halide melts. Materials Research. 2018;21(4): e20170648 . https://doi.org/10.1590/19805373-mr-2017-0648

103. Zavrazhnov A., Naumov A., Kosykov A., Kovygin Y. New way of the skeletal metal synthesis. J. Fudan University (Fudan Xuebao, China). 2007;46(5): 786.

104. Kosyakov A. V., Zavrazhnov A. Y., Naumov A. V., Nazarova A. A., Zlomanov V. P. Chemical vapor transport: A viable approach to controlling the composition of intermetallic phases promising for catalyst engineering. Inorganic Materials. 2007;43(11): 1199-1205. https://doi.org/10.1134/S0020168507110088

105. Kosyakov A. V., Zavrazhnov A. Yu. Equilibrium in the reaction between nickel or gallium in nickel solid solutions and of with carbon monoxide Kondensirovannye sredy $i$ mezhfaznye granitsy = Condensed Matter and Interphases. 2017;19(1): 68-79. Available at: https://www.elibrary.ru/item.asp?id=29033318 (In Russ., abstract in Eng.)

106. Zavrazhnov A. Yu., Kosyakov A. V., Sergeeva A. V., Berezin S. S., Chernenko K. K. High-temperature in situ vapor spectrophotometry as a static variant of tensimetric method equilibria in the Ga-I system. Kondensirovannye sredy $i$ mezhfaznye granitsy = Condensed Matter and Interphases. 2015;17(4): 417-436. Available at: https://www.elibrary.ru/item.asp?id=25946578 (In Russ., abstract in Eng.)

107. Zavrazhnov A. Yu., Naumov A. V., Malygina E. N., Kosyakov A. V. Indium monochloride vapor pressure: the vapor-gauge and spectrophotometric experimaental data. Kondensirovannye sredy i mezhfaznye granitsy = Condensed Matter and Interphases. 2019;21(1): 60-71. https://doi.org/10.17308/kcmf.2019.21/717

108. Berezin S. S. Fazovye ravnovesiya v sistemakh Fe-S, Ga-S i sintez sul'fidov galliya i zheleza s ispol'zovaniem galogenidov $\mathrm{FeX}_{2}(\mathrm{X} \neq \mathrm{F})$ и $\mathrm{GaI}_{3}$. Diss. Cand. Chem. Sciences / Voronezh: Voronezh State University; 2018. 239 p. Available at: https://www.dissercat.com/content/ fazovye-ravnovesiya-v-sistemakh-fe-s-ga-s-i-sintezsulfidov-galliya-i-zheleza-s-ispolzovanie (In Russ.).

109. Zavrazhnov A. Y., Berezin S. S., Kosykov A., Naumov A., Berezina M., Brezhnev N. The phase diagram of the $\mathrm{Ga}-\mathrm{S}$ system in the concentration range of 48.0-60.7 mol\%. Journal of Thermal Analysis and Calorimetry. 2018;134(1): 483-492 https://doi.org/10.1007/ s10973-018-7124-z

110. Volkov V. V., Sidey V. I., Naumov A. V., Nekrylov I. N., Brezhnev N. Yu.; Malygina E. N., Zavrazhnov A. Yu. The cubic high-temperture modification of gallium sulphide ( $\mathrm{xS}=59 \mathrm{~mol} \%$ ) and the $\mathrm{T}$, $\mathrm{x}$-diagram of the $\mathrm{Ga}$ - S system Kondensirovannye sredy i mezhfaznye granitsy = Condensed Matter and Interphases. 2019;21(1): 37-50. https://doi.org/10.17308/kcmf.2019.21/715

\section{Information about the authors}

Galina V. Semenova, DSc in Chemistry, Professor, Department of General and Inorganic Chemistry, Voronezh State University, Voronezh, Russian Federation; e-mail: semen157@chem.vsu.ru. ORCID iD: htpps://orcid.org/0000-003-3877-985X.

Alexander Yu. Zavrazhnov, DSc in Chemistry, Professor, Department of General and Inorganic Chemistry, Voronezh State University; Voronezh, Russian Federation; e-mail: Alzavr08@rambler.ru. ORCID iD: htpps://orcid.org/ 0000-0003-0241-834X.

Received 24 June 2021; Approved after reviewing 15 July 2021; Accepted 15 August 2021; Published online 25 September 2021.

Translated by Irina Charychanskaya Edited and proofread by Simon Cox 